\title{
Greenland Ice Sheet influence on Last Interglacial climate: global sensitivity studies performed with an atmosphere-ocean general circulation model
}

\author{
Madlene Pfeiffer ${ }^{1}$ and Gerrit Lohmann ${ }^{1,2}$ \\ ${ }^{1}$ Alfred Wegener Institute, Helmholtz Centre for Polar and Marine Research, Bussestraße 24, 27570 Bremerhaven, Germany \\ ${ }^{2}$ Department of Physics/Electrical Engineering, Institute of Environmental Physics, University of Bremen, \\ Otto-Hahn-Allee 1, 28359 Bremen, Germany
}

Correspondence to: Madlene Pfeiffer (madlene.pfeiffer@awi.de)

Received: 26 February 2015 - Published in Clim. Past Discuss.: 30 March 2015

Revised: 14 April 2016 - Accepted: 2 May 2016 - Published: 8 June 2016

\begin{abstract}
During the Last Interglacial (LIG, $\sim 130$ 115 kiloyears (kyr) before present (BP)), the northern high latitudes were characterized by higher temperatures than those of the late Holocene and a lower Greenland Ice Sheet (GIS). However, the impact of a reduced GIS on the global climate has not yet been well constrained. In this study, we quantify the contribution of the GIS to LIG warmth by performing various sensitivity studies based on equilibrium simulations, employing the Community Earth System Models (COSMOS), with a focus on height and extent of the GIS. We present the first study on the effects of a reduction in the GIS on the surface temperature (TS) on a global scale and separate the contribution of astronomical forcing and changes in GIS to LIG warmth. The strong Northern Hemisphere summer warming of approximately $2{ }^{\circ} \mathrm{C}$ (with respect to preindustrial) is mainly caused by increased summer insolation. Reducing the height by $\sim 1300 \mathrm{~m}$ and the extent of the GIS does not have a strong influence during summer, leading to an additional global warming of only $+0.24^{\circ} \mathrm{C}$ compared to the purely insolation-driven LIG. The effect of a reduction in the GIS is, however, strongest during local winter, with up to $+5^{\circ} \mathrm{C}$ regional warming and with an increase in global average temperature of $+0.48^{\circ} \mathrm{C}$.

In order to evaluate the performance of our LIG simulations, we additionally compare the simulated TS anomalies with marine and terrestrial proxy-based LIG temperature anomalies derived from three different proxy data compilations. Our model results are in good agreement with proxy records with respect to the warming pattern but underesti-
\end{abstract}

mate the magnitude of temperature change when compared to reconstructions, suggesting a potential misinterpretation of the proxy records or deficits in our model. However, we are able to partly reduce the mismatch between model and data by additionally taking into account the potential seasonal bias of the proxy record and/or the uncertainties in the dating of the proxy records for the LIG thermal maximum. The seasonal bias and the uncertainty of the timing are estimated from new transient model simulations covering the whole LIG. The model-data comparison improves for proxies that represent annual mean temperatures when the GIS is reduced and when we take the local thermal maximum during the LIG (130-120 kyr BP) into account. For proxy data that represent summer temperatures, changes in the GIS are of minor importance for sea surface temperatures. However, the annual mean and summer temperature change over Greenland in the reduced GIS simulations seems to be overestimated as compared to the local ice core data, which could be related to the interpretation of the recorder system and/or the assumptions of GIS reduction. Thus, the question regarding the real size of the GIS during the LIG has yet to be answered.

\section{Introduction}

One important application of atmosphere-ocean general circulation models (AOGCMs) is the computation of future climate projections (Collins et al., 2013; Kirtman et al., 2013), which allow insight into possible future climate states that may be notably different from present day. In order to en- 
sure the reliability of such climate projections, the climate models' ability to replicate climate states that are different from the present needs to be tested (e.g. Braconnot et al., 2012; Flato et al., 2013). Past time periods provide the means for evaluating the performance of general circulation models (e.g. Dowsett et al., 2013; Lohmann et al., 2013; Lunt et al., 2013).

In particular, the simulation of interglacial climates provides an example of how models can respond to well known changes in astronomical forcing (Mearns et al., 2001) and the possibility to analyse the main drivers leading to an interglacial climate that was warmer than the present interglacial. The Last Interglacial (LIG, 130-115 kiloyears (kyr) before present (BP)) is considered to be on average warmer than the Holocene (10-0 kyr BP) (CLIMAP Project Members, 1984; Martinson et al., 1987; Kukla et al., 2002; Bauch and Erlenkeuser, 2003; Felis et al., 2004; Kaspar et al., 2005; Jansen et al., 2007; Turney and Jones, 2010; Masson-Delmotte et al., 2013). Model simulations indicate a pronounced warming during boreal summer in northern high latitudes (Harrison et al., 1995; Kaspar et al., 2005; Otto-Bliesner et al., 2006; Lohmann and Lorenz, 2007; Stone et al., 2013). Proxy records located in the Northern Hemisphere indicate also that LIG climate is characterized by temperatures that are several degrees Celsius above pre-industrial values in several regions (Kaspar et al., 2005; CAPE-Last Interglacial Project Members, 2006; Turney and Jones, 2010; Mckay et al., 2011). Simulated winter in high latitudes is considered to be warmer during the LIG due to sea ice feedbacks (Montoya et al., 2000; Kaspar et al., 2005; Yin and Berger, 2010). One cause of LIG summer warmth was increased summer insolation at middle to high latitudes. Greenhouse gas (GHG) concentrations during the LIG were similar to the pre-industrial period (PI) (Bakker et al., 2014).

Studies based on reconstructions and climate model simulations suggest a partial or complete absence of the Greenland Ice Sheet (GIS) during the LIG, and that the sea level was higher than the PI (Veeh, 1966; Stirling et al., 1998; Cuffey and Marshall, 2000; Otto-Bliesner et al., 2006; Overpeck et al., 2006; Jansen et al., 2007; Kopp et al., 2009, 2013; Alley et al., 2010; van de Berg et al., 2011; Robinson et al., 2011; Dutton and Lambeck, 2012; Quiquet et al., 2013; Church et al., 2013; Stone et al., 2013), while a more recent study based on ice core data proposes only a modest GIS change (i.e. equivalent to a contribution to sea level rise of $\sim 2 \mathrm{~m}$; NEEM community members, 2013; MassonDelmotte et al., 2013). An increase in sea level during the LIG is estimated to be between 6 and $9 \mathrm{~m}$ (Kopp et al., 2009; Dutton et al., 2015), with a possible contribution of 3 to $4 \mathrm{~m}$ from Antarctica (Sutter et al., 2016). The contribution of a partially melted GIS to LIG sea level rise is, however, not yet well determined; various studies suggest a sea level rise due to meltwater from Greenland of +0.3 to $+5.5 \mathrm{~m}$ (Cuffey and Marshall, 2000; Tarasov and Peltier, 2003; Lhomme et al., 2005; Otto-Bliesner et al., 2006; Colville et al., 2011; Qui- quet et al., 2013; Stone et al., 2013), part of the uncertainty arising from different climate scenarios used to assess the ice sheet response.

Existing studies on the effects of a reduced GIS during the LIG have been centred mostly on the Northern Hemisphere and focused on implications related to sea level rise (Stone et al., 2013) and Atlantic Meridional Overturning Circulation (AMOC) (Bakker et al., 2012). The studies by Bakker et al. (2012) and Stone et al. (2013) assume a relatively modest reduction of the GIS and find a mismatch between the simulated and the proxy-based temperature anomalies with respect to PI (CAPE-Last Interglacial Project Members, 2006). Otto-Bliesner et al. (2006) find that a GIS elevation reduced by $500 \mathrm{~m}$ leads to a pronounced warming of up to $+5^{\circ} \mathrm{C}$ in middle- to high-latitude summer. However, they also find a mismatch between model and data, with the model underestimating the temperature anomaly indicated by the proxy record. In an LIG study based on transient climate model simulations performed with an Earth system model of intermediate complexity (EMIC), Loutre et al. (2014) find that changes in the Northern Hemisphere ice sheet configuration (extent and albedo) have only a small impact on the climate at the beginning of the LIG. They find as well that the model underestimates the magnitude of the temperature change when compared to reconstructions.

Other model-data comparison studies for the LIG (Lunt et al., 2013; Otto-Bliesner et al., 2013) based on AOGCMs (but with no changes in GIS elevation or extent) also show an underestimation of reconstructed temperature anomalies (Turney and Jones, 2010; McKay et al., 2011). Bakker and Renssen (2014), who perform an analysis of transient simulations for the LIG, provide a partial explanation for the model-data mismatch, proposing that such large differences between the reconstructed and simulated LIG temperatures may stem from the fact that commonly used climate syntheses represent a single time slice assuming synchronous LIG thermal maximum in space and time. Their study suggests that global compilations of reconstructed LIG thermal maximum overestimate the warming. However, different studies (modelling as well as proxy-based) indicate that the maximum LIG warmth occurred at different times throughout the LIG depending on the geographical location (Bakker et al., 2012; Govin et al., 2012; Langebroek and Nisancioglu, 2014). The lack of climate synthesis for the LIG going further than proposing a single snapshot on LIG maximum warmth and thus accounting for asynchronous changes across the globe is due to the difficulty in building robust and coherent age models for different climatic archives during the LIG (Govin et al., 2015). Recently, Capron et al. (2014) have proposed a new climate synthesis for the high-latitude regions based on a coherent temporal framework between ice and marine archives. This allows for the first time to assess both the temporal and the spatial evolution of the climate throughout the LIG (Capron et al., 2014). 
Transient LIG climate simulations provide the possibility to determine when and where maximum LIG warmth occurred, and whether a given record may be seasonally biased or rather represents annual mean temperatures. Therefore, transient climate simulations may help to clarify the origin of the disagreement between model and data. In this study, we analyse the effect of a reduced GIS on LIG global climate with a focus on surface temperature (TS) at $130 \mathrm{kyr}$ BP. The TS is derived from equilibrium simulations performed with an AOGCM. We perform several sensitivity simulations with different boundary conditions and use three different methods of reducing GIS elevation to half its pre-industrial elevation and/or extent. This approach enables us to determine what GIS configuration has the strongest impact on the global temperature. Additionally, we assess the importance of insolation and albedo. Furthermore, in order to validate our results, we perform a model-data comparison using three different proxy-based temperature compilations by CAPE-Last Interglacial Project Members (2006), Turney and Jones (2010), and Capron et al. (2014). For model-data comparison, we additionally consider the timing uncertainty on the maximum LIG warmth as determined from our transient simulations as well as the potential seasonal bias of the proxy record.

\section{Data and methods}

\subsection{Model description}

The Community Earth System Models (COSMOS) consist of the general atmosphere circulation model ECHAM5 (5th generation of the European Centre Hamburg Model; Roeckner et al., 2003); the land surface and vegetation model JSBACH (Jena Scheme of Atmosphere Coupling in Hamburg; Raddatz et al., 2007); the general ocean circulation model MPIOM (Max Planck Institute Ocean Model; Marsland et al., 2003); and the OASIS3 coupler (Ocean-AtmosphereSea Ice-Soil; Valcke et al., 2003; Valcke, 2013), which enables the atmosphere and ocean to interact with each other. COSMOS is mainly developed at the Max Planck Institute for Meteorology in Hamburg (Germany). The atmospheric component ECHAM5 is a spectral model, which is used in this study at a horizontal resolution of $\mathrm{T} 31\left(\sim 3.75^{\circ} \times 3.75^{\circ}\right)$ with a vertical resolution of 19 hybrid sigma-pressure levels, the highest level being located at $10 \mathrm{hPa}$. JSBACH simulates fluxes of energy, momentum, and $\mathrm{CO}_{2}$ between land and atmosphere and comprises the dynamic vegetation module by Brovkin et al. (2009), which enables the terrestrial plant cover to explicitly adjust to variations in the climate state. MPIOM is formulated on a bipolar orthogonal spherical coordinate system. We employ it at a horizontal resolution of GR30 (corresponding to $\sim 3^{\circ} \times 1.8^{\circ}$ ) with 40 vertical levels. MPIOM includes a Hibler-type zero-layer dynamicthermodynamic sea ice model with viscous plastic rheology (Semtner, 1976; Hibler, 1979). No flux correction is ap- plied (Jungclaus et al., 2006). Model time steps are $40 \mathrm{~min}$ (atmosphere) and $144 \mathrm{~min}$ (ocean). This COSMOS configuration has been applied for the mid- and early Holocene (Wei and Lohmann, 2012), glacial conditions (Gong et al., 2013; Zhang et al., 2013, 2014), the Pliocene (Stepanek and Lohmann, 2012), the Miocene (Knorr et al., 2011; Knorr and Lohmann, 2014), future climate projections (Gierz et al., 2015), and the LIG (Lunt et al., 2013; Pfeiffer and Lohmann, 2013; Bakker et al., 2014; Felis et al., 2015; Gong et al., 2015; Jennings et al., 2015).

\subsection{Experimental setup}

As control climate, we use a PI simulation described by Wei et al. (2012). Greenhouse gas concentrations and astronomical forcing of the PI simulation are prescribed according to the Paleoclimate Modelling Intercomparison Project Phase 2 (PMIP2) protocol (Braconnot et al., 2007). Several equilibrium simulations covering the LIG are performed using fixed boundary conditions for 130 and $125 \mathrm{kyr}$ BP time slices. The latter simulation is performed in order to assess whether a reduction in the GIS at $125 \mathrm{kyr} \mathrm{BP}$ improves the agreement between the model and the three proxy compilations considered in this study (CAPE-Last Interglacial Project Members, 2006; Turney and Jones, 2010; 125 kyr BP time slice by Capron et al., 2014). Astronomical parameters for the time slices considered in this study have been calculated according to Berger (1978) and are given in Table 1. It is known that one main driver for LIG climate is the Earth's astronomical parameters (Kutzbach et al., 1991; Crowley and Kim, 1994; Montoya et al., 2000; Felis et al., 2004; Kaspar and Cubasch, 2007). During the early part of the LIG, the axial tilt (obliquity) was higher which caused stronger summer insolation at high latitudes of the Northern Hemisphere, while the low latitudes received less insolation; this effect manifests in enhanced seasonality (i.e. warmer summers and cooler winters) in the early LIG climate. The Earth's orbital eccentricity was more than twice the present-day value (Berger and Loutre, 1991), and boreal summer coincided with the Earth passing the perihelion (Laskar et al., 2004; Yin and Berger, 2010).

Our main focus is the effects of height and extent of the GIS and of insolation changes on climate; consequently, GHG concentrations are prescribed at mid-Holocene levels (278 parts per million by volume (ppmv) $\mathrm{CO}_{2}, 650$ parts per billion by volume (ppbv) $\mathrm{CH}_{4}$, and 270 ppbv $\mathrm{N}_{2} \mathrm{O}$, Table 1). An additional simulation is performed using values for $\mathrm{GHG}$ concentrations proposed in the Paleoclimate Modelling Intercomparison Project Phase 3 (PMIP3) for the $130 \mathrm{kyr}$ BP time slice (e.g. Lunt et al., 2013) and corresponding to $257 \mathrm{ppmv}$ for $\mathrm{CO}_{2}, 512 \mathrm{ppbv}$ for $\mathrm{CH}_{4}$, and $239 \mathrm{ppbv}$ for $\mathrm{N}_{2} \mathrm{O}$ (LIGGHG, Table 1, Fig. S1 in the Supplement). This simulation is included in the Supplement as a control run for the GHG concentrations used in our LIG sensitivity simulations in order to show that there is no large-scale impact of lower GHG concentrations relative to our LIG control simulation 
Table 1. Overview of model configuration and climate forcings. PI: pre-industrial; Veg.: vegetation; dyn.: dynamic; $e$ : eccentricity; $\varepsilon$ : obliquity; $\omega$ : length of perihelion. The Greenland Ice Sheet (GIS) configurations are displayed in Fig. 1.

\begin{tabular}{llllllllll}
\hline Simulation & $\begin{array}{l}\text { Time } \\
(\mathrm{kyr} B P)\end{array}$ & $\begin{array}{l}\mathrm{CO}_{2} \\
(\mathrm{ppmv})\end{array}$ & $\begin{array}{l}\mathrm{CH}_{4} \\
(\mathrm{ppbv})\end{array}$ & $\begin{array}{l}\mathrm{N}_{2} \mathrm{O} \\
(\mathrm{ppbv})\end{array}$ & $\begin{array}{l}\text { Greenland } \\
\text { Ice Sheet }\end{array}$ & Veg. & $e$ & $\begin{array}{l}\varepsilon \\
\left({ }^{\circ}\right)\end{array}$ & $\begin{array}{l}\omega \\
\left({ }^{\circ}\right)\end{array}$ \\
\hline LIG-ctl & 130 & 278 & 650 & 270 & $\mathrm{PI}$ & dyn. & 0.0382 & 24.24 & 49.1 \\
LIG- $\times 0.5$ & 130 & 278 & 650 & 270 & $\times 0.5$ & dyn. & 0.0382 & 24.24 & 49.1 \\
LIG-1300m & 130 & 278 & 650 & 270 & $-1300 \mathrm{~m}$ & dyn. & 0.0382 & 24.24 & 49.1 \\
LIG-1300m-alb & 130 & 278 & 650 & 270 & $-1300 \mathrm{~m}+$ alb & dyn. & 0.0382 & 24.24 & 49.1 \\
LIG-1300m-alb-CH & 130 & 280 & 760 & 270 & $-1300 \mathrm{~m}+$ alb & dyn. & 0.0382 & 24.24 & 49.1 \\
LIG-GHG* & 130 & 257 & 512 & 239 & PI & PI & 0.0382 & 24.24 & 49.1 \\
LIG-125k* & 125 & 278 & 650 & 270 & $-1300 \mathrm{~m}+$ alb & dyn. & 0.0400 & 23.79 & 128.1 \\
PI & 0 & 280 & 760 & 270 & PI & dyn. & 0.0167 & 23.45 & 282.2 \\
LIG-ctl-tr & $130-115$ & 278 & 650 & 270 & PI & dyn. & varying & varying & varying \\
LIG- $\times 0.5-t r$ & $130-115$ & 278 & 650 & 270 & $\times 0.5$ & dyn. & varying & varying & varying \\
LIG-1300m-alb-tr & $130-115$ & 278 & 650 & 270 & $-1300 \mathrm{~m}+$ alb & dyn. & varying & varying & varying \\
LIG-GHG-tr & $130-115$ & varying & varying & varying & PI & PI & varying & varying varying \\
HOL-tr & $8-0$ & 278 & 650 & 270 & PI & dyn & varying & varying & varying \\
\hline
\end{tabular}

* Simulations presented in the Supplement.

(Fig. S1). Another LIG simulation is forced with increased $\mathrm{CH}_{4}(760 \mathrm{ppbv})$ and slightly increased $\mathrm{CO}_{2}(280 \mathrm{ppmv})$ in order to have one LIG simulation that has identical GHG concentrations to the ones prescribed in the PI simulation (Wei et al., 2012) (Table 1).

The size of the GIS during the LIG is not well constrained by reconstructions (Koerner, 1989; Koerner and Fisher, 2002; NGRIP members, 2004; Johnsen and Vinther, 2007; Willerslev et al., 2007; Alley et al., 2010; NEEM community members, 2013). We take this uncertainty into account and perform sensitivity simulations with three different elevations and two different ice sheet areas of the GIS (Fig. 1). An LIG simulation with a pre-industrial GIS elevation (LIG-ctl, Table 1, Fig. 1a) is used as a control run for our LIG simulations, which allows us to quantify the exclusive effects of Greenland elevation on climate. Four simulations are performed using a modified GIS (Table 1). We consider the following four options:

1. A GIS lowered to half its pre-industrial elevation with unchanged GIS area (LIG- $\times 0.5$, Fig. 1b).

2. A GIS lowered by $1300 \mathrm{~m}$ (LIG-1300m); at locations where the pre-industrial Greenland elevation is below $1300 \mathrm{~m}$, we set LIG orography to $0 \mathrm{~m}$, but define the ground to be ice-covered and keep the albedo at values typical for the GIS (Fig. 1c).

3. A GIS similar to LIG-1300m, but with albedo adjustment at locations where prescribed LIG orography is $0 \mathrm{~m}$ (LIG-1300m-alb); at such locations the land surface is defined as being ice-free and the background albedo is reduced from 0.7 to 0.16 (Fig. 1d), an albedo value that is typical for tundra (Fitzjarrald and Moore, 1992; Eugster et al., 2000). This simulation, in combination with LIG-1300m and LIG-ctl, allows us to separate the climatic effects of a lowered and spatially reduced GIS from those of changes in albedo.

4. A simulation similar to (3), but with an atmospheric concentration of $\mathrm{CH}_{4}$ that is increased to $760 \mathrm{ppbv}$ (LIG-1300m-alb-CH 4 , Fig. 1d); this simulation enables us to quantify the combined effect of a lowered GIS elevation, changes in albedo, and insolation with respect to PI.

Such changes in GIS elevation and extent would lead to a sea level rise of about $3 \mathrm{~m}$ for the present situation due to the post-glacial rebound effect, when assuming no elastic lithosphere deformation (Fowler, 2004). A sea level change of $+3 \mathrm{~m}$ is in agreement with other studies that suggest an increase in sea level of 0.3 to $5.5 \mathrm{~m}$ during the LIG as a result of GIS melting (Cuffey and Marshall, 2000; Tarasov and Peltier, 2003; Lhomme et al., 2005; Otto-Bliesner et al., 2006; Carlson et al., 2008; Colville et al., 2011; Quiquet et al., 2013; Stone et al., 2013). It is, however, not compatible with the elevation change inferred from the air content at North Greenland Eemian Ice Drilling (NEEM) (NW Greenland), which suggests a decrease in elevation of less than $400 \mathrm{~m}$ (albeit with a large uncertainty) starting from an ice sheet thicker than today at the end of the penultimate deglaciation, and along the LIG period (NEEM community members, 2013).

Generally, other boundary conditions of the simulations are kept at their pre-industrial state, except for vegetation, which is computed dynamically according to the prevailing climate conditions (the only equilibrium simulation that considers fixed pre-industrial vegetation is LIG-GHG).

Furthermore, we perform one transient model simulation that covers the Holocene (8-0 kyr BP) and four transient simulations of the LIG (130-115 kyr BP). The Holocene tran- 


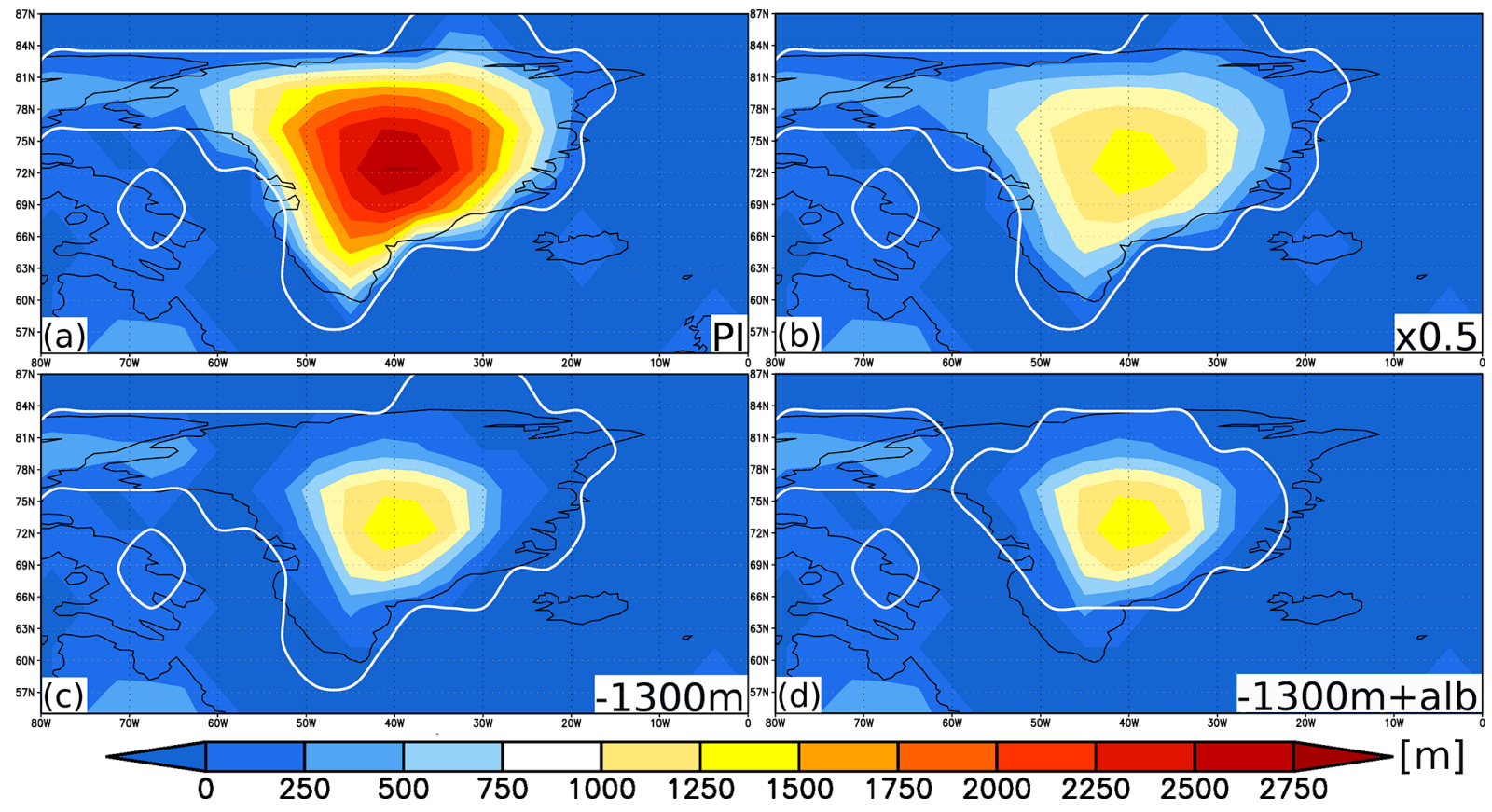

Figure 1. Greenland Ice Sheet (GIS) elevation and land ice cover prescribed in our model simulations: (a) pre-industrial GIS and land ice mask, (b) $\times 0.5$ GIS and pre-industrial land ice mask, (c) $-1300 \mathrm{~m}$ GIS and pre-industrial land ice mask, and (d) $-1300 \mathrm{~m}$ and adjusted land ice mask. In (a), the pre-industrial elevation and land ice mask are unchanged. In (b), the pre-industrial elevation over the GIS area is multiplied by 0.5 ; the land ice mask is unchanged. In (c), for each grid point over the GIS, $1300 \mathrm{~m}$ is subtracted from pre-industrial elevation; the land ice mask is unchanged. In (d), for each grid point over the GIS, $1300 \mathrm{~m}$ is subtracted from pre-industrial elevation; at grid locations where the elevation is lower than $1300 \mathrm{~m}$, land ice is removed and albedo is adjusted accordingly.

sient simulation is included in this study as a control run for the LIG transient simulations in order to assess the differences and similarities between the present and LIG. For the LIG, we apply orography configurations of LIG-ctl, LIG$\times 0.5$, LIG-1300m-alb, and LIG-GHG, respectively. These LIG transient simulations enable us to extract the temperatures at the LIG thermal maximum. The transient simulations are started from a near-equilibrium state, meaning that the climate system is already adjusted to the prescribed forcings, except for the ocean, which needs about 3000 years in order to reach an equilibrium state. Performing such long equilibrium simulations is not feasible due to the involved computational effort. Each transient simulation is accelerated by a factor of 10 in order to reduce the computational expense. To this end, astronomical forcing is accelerated following the method of Lorenz and Lohmann (2004). The astronomical parameters are calculated after Berger (1978). During the simulations, the greenhouse gas concentrations remain fixed - except for LIG-GHG-tr, where a time series is prescribed according to Lüthi et al. (2008) for $\mathrm{CO}_{2}$, Loulergue et al. (2008) for $\mathrm{CH}_{4}$, and Spahni et al. (2005) for $\mathrm{N}_{2} \mathrm{O}$, as proposed for PMIP3. The respective values are interpolated to a $0.01 \mathrm{kyr}$ resolution that corresponds to the accelerated model time axis. A fixed pre-industrial vegetation is considered only in the LIG-GHG-tr; in the other transient simula- tions, vegetation is computed dynamically. For the Holocene run, the orography is identical to pre-industrial conditions.

In order to determine whether TS anomalies between simulations are statistically significant or rather caused by internal variability (noise), we perform an independent two-tailed Student's $t$ test following Eq. (1). For each grid cell, it relates time averages $X$ and standard deviations $\sigma$ of model output time series of two given model simulations $X_{1}$ and $X_{2}$ of a length of $n$ time steps, depending on the effective degrees of freedom $\left(\mathrm{DOF}_{\text {eff }}\right)$. The $\mathrm{DOF}_{\text {eff }}$ are calculated considering the lag-1 autocorrelation acf (von Storch and Zwiers, 1999):

$\mathrm{DOF}_{\text {eff }}=n(1-\mathrm{acf}) /(1+$ acf $)$ with acf $=\max ($ acf, 0$)$,

meaning that the $\mathrm{DOF}_{\text {eff }}$ cannot be higher than 50 , as the last 50 model years of each simulation are used for the analysis. For each grid point from $X_{1}$ and $X_{2}$ simulations, the smaller

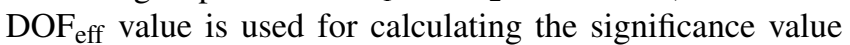
with a $95 \%$ confidence interval.

$t=\frac{\overline{X_{1}}-\overline{X_{2}}}{\sqrt{\frac{\sigma^{2}\left(X_{1}\right)}{n}+\frac{\sigma^{2}\left(X_{2}\right)}{n}}}$

Surface temperature at locations where the $t$ test of two data sets indicates a significance value below the critical value is considered to be statistically insignificant and is marked 
by hatches on geographical maps presented throughout this study.

For the analysis of time slice simulations, we define winter and summer as the mean of the 50 coldest and warmest months, respectively, for each grid cell, as we are mainly interested in local seasons. In all performed simulations, a modern calendar is assumed. Although in reality the definition of seasons changes over time due to orbital precession (Joussaume and Braconnot, 1997; Lorenz and Lohmann, 2004), taking this calendar shift into account would only have a minor influence on our results since we calculate the summer and winter seasons by extracting the warmest and coldest month, respectively. Maximum and minimum LIG TS are calculated from the transient simulations considering the time interval between 130 and $120 \mathrm{kyr}$ BP. In order to filter out internal variability, a 100-point running average representing the average over 1000 calendar years is applied. Maximum and minimum LIG warmth of the summer are defined as the warmest and coldest average of 100 warmest months, respectively, which reflects the warmest or coldest 1000 summer seasons with respect to the astronomical forcing. For the maximum and minimum LIG warmth of annual mean, we consider the warmest and coldest average of 100 model years, respectively. The seasonality range is defined by calculating the summer maximum LIG warmth (warmest average of 100 warmest months of the model years) and winter minimum LIG TS (coldest average of 100 coldest months of the model years).

\subsection{Temperature reconstructions}

In order to test the robustness of our simulations, we additionally perform a model-data comparison using proxybased temperature anomalies that are available for the northern high latitudes (CAPE-Last Interglacial Project Members, 2006), across the globe (Turney and Jones, 2010), and in middle to high latitudes (Capron et al., 2014). The temperature reconstructions from CAPE-Last Interglacial Project Members (2006) are based on terrestrial and marine proxy records and estimate summer temperatures for maximum LIG warmth relative to PI. The global data set by Turney and Jones (2010) comprises terrestrial and marine proxy records and estimates annual mean temperatures for maximum LIG warmth (terrestrial) and for the period of levelled $\delta^{18} \mathrm{O}$ (marine), relative to present day (PD, 1961-1990; Smith and Reynolds, 1998; New et al., 1999). The high-latitude climate synthesis by Capron et al. (2014) provides temporal air and sea surface temperature (SST) reconstructions based on ice core and marine records, respectively, across the interval 115 to $130 \mathrm{kyr}$ BP (in our study covering the period between 125 and $115 \mathrm{kyr}$ BP). They also propose snapshots of surface temperature anomalies and associated quantitative uncertainties at $115,120,125$, and $130 \mathrm{kyr} \mathrm{BP}$, but here we use the last two snapshots. Detailed information regarding the proxy data is given in CAPE-Last Interglacial Project Members (2006),
Turney and Jones (2010), and Capron et al. (2014), respectively.

In order to quantify the agreement between model and data, we calculate the root-mean-square deviation (RMSD) which is a measure of the differences between an estimator $\left(y_{\text {model }}\right)$ and estimated parameter $\left(y_{\text {data }}\right)$ (Gauss and Stewart, 1995; Mudelsee, 2010). RMSD is defined in Eq. (2):

$\mathrm{RMSD}=\sqrt{\frac{1}{n} \sum_{i=1}^{n}\left(y_{\text {model }}-y_{\text {data }}\right)^{2}}$,

where $y_{\text {model }}$ is the simulated TS anomaly at the location of the proxy record, $y_{\text {data }}$ indicates the reconstructed TS anomaly, and $n$ is the number of data samples.

\section{Results}

In the first part of this section, we present results from our LIG GIS sensitivity simulations, focusing on TS anomalies. Afterwards, a short description of results from the transient simulations is presented, followed by the model-data comparison and consideration of potential uncertainties in the data.

\subsection{Greenland Ice Sheet elevation and albedo influence on global surface temperature}

\subsubsection{Annual mean anomalies}

Figure 2 shows the TS changes of lowering GIS by various methods. We observe the strongest warming over Greenland (of up to $+12.5^{\circ} \mathrm{C}$ ) in LIG-1300m-alb (Figs. 1d and 2c). Northern North America and the Arctic Ocean warm by up to $+2{ }^{\circ} \mathrm{C}$ in all GIS sensitivity simulations. A pronounced warming is found over the southernmost Southern Ocean of up to $+4{ }^{\circ} \mathrm{C}$ (Fig. 2a-c).

Considering all LIG sensitivity simulations, the highest TS mean anomalies globally and in the Southern Hemisphere are simulated in LIG-1300m-alb, with an average of $\Delta \mathrm{TS}=+0.37^{\circ} \mathrm{C}$ and $\Delta \mathrm{TS}=+0.31^{\circ} \mathrm{C}$, respectively (Table 2). However, for the Northern Hemisphere, the highest average TS anomaly of $\Delta \mathrm{TS}=+0.47^{\circ} \mathrm{C}$ is found in LIG$\times 0.5$ (Table 2). Consequently, the exact method of changing GIS configuration influences the hemispheric temperature anomalies.

The most affected areas by changes in GIS configuration are the northern high latitudes, which experience a warming of $\Delta \mathrm{TS}=+1.45^{\circ} \mathrm{C}$ in LIG-1300m-alb, as well as $\Delta \mathrm{TS}=+1.07^{\circ} \mathrm{C}$ and $\Delta \mathrm{TS}=+1.03^{\circ} \mathrm{C}$ in LIG- $\times 0.5$ and LIG-1300m, respectively. This indicates that albedo plays a significant role in the temperature changes over northern high latitudes, where it is causing an average temperature anomaly of $\Delta \mathrm{TS}=+0.42^{\circ} \mathrm{C}$. A local cooling of up to $-1.60^{\circ} \mathrm{C}$ is limited to the Barents Sea in LIG- $\times 0.5$ and 
LIG-x0.5 minus LIG-ctI

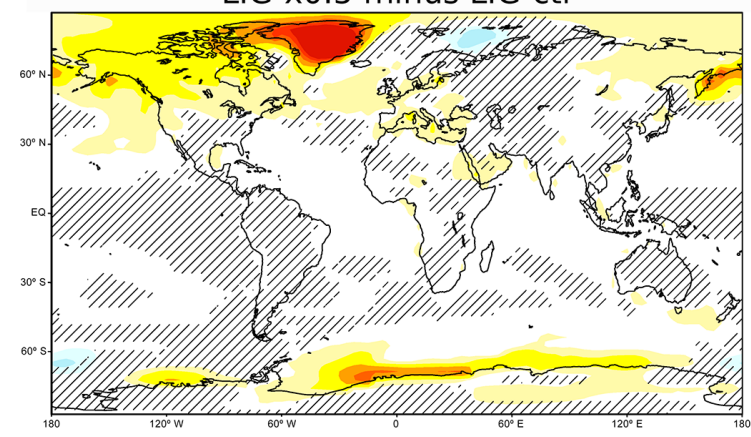

(a)

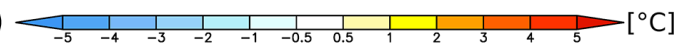

LIG-1300m-alb minus LIG-ct|

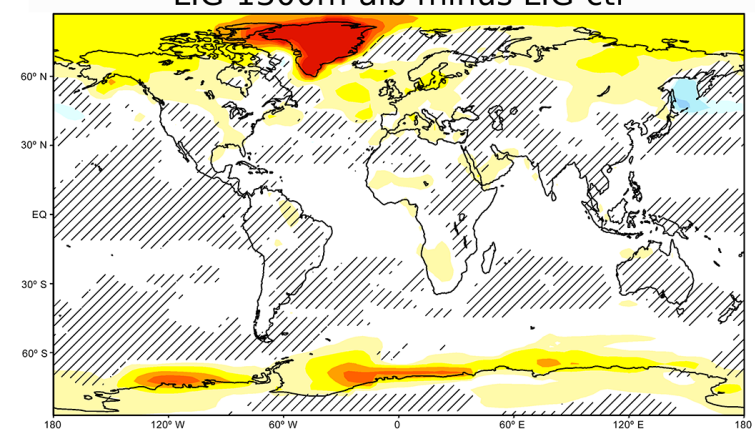

(c)

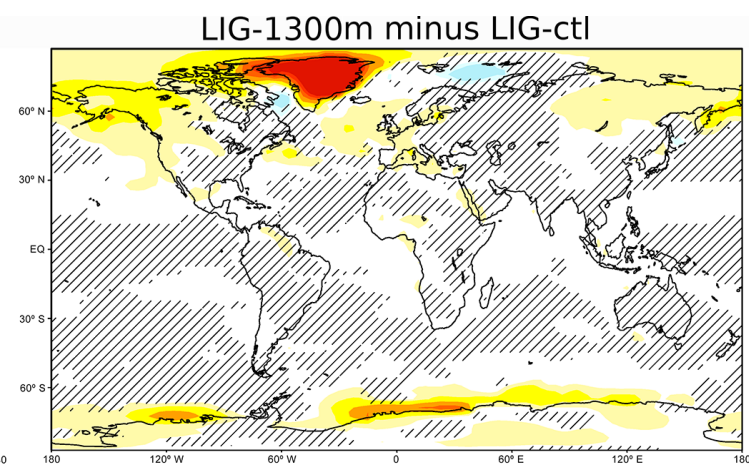

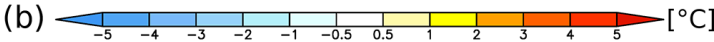

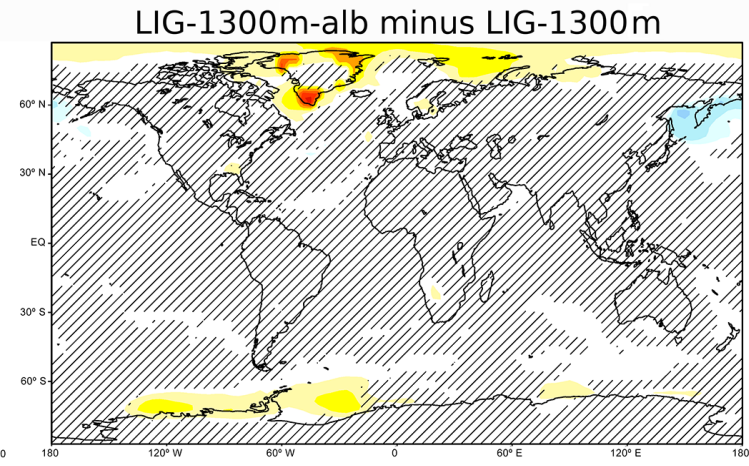

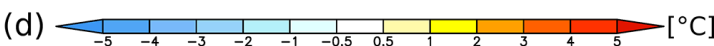

Figure 2. Effect of (a-c) Greenland Ice Sheet elevation and $(\mathbf{c}, \mathbf{d})$ albedo in the $130 \mathrm{kyr}$ BP simulations. Annual mean surface temperature (TS) anomalies for (a) LIG- $\times 0.5$ minus LIG-ctl, (b) LIG-1300m minus LIG-ctl, (c) LIG-1300m-alb minus LIG-ctl, and (d) LIG-1300m-alb minus LIG-1300m. Hatched areas mark statistically insignificant TS anomalies.

Table 2. Atlantic Meridional Overturning Circulation (AMOC) and absolute values of surface temperature (TS) for global, Northern Hemisphere $(\mathrm{NH})$, and Southern Hemisphere ( $\mathrm{SH}$ ) coverage, calculated for annual mean, local summer mean (warmest month), and local winter mean (coldest month).

\begin{tabular}{lcccc|ccc|ccc}
\hline & & \multicolumn{3}{c}{ Annual mean TS $\left({ }^{\circ} \mathrm{C}\right)$} & \multicolumn{2}{c|}{ Winter mean TS $\left({ }^{\circ} \mathrm{C}\right)$} & \multicolumn{3}{c}{ Summer mean TS $\left({ }^{\circ} \mathrm{C}\right)$} \\
\cline { 3 - 10 } Simulation & AMOC $(\mathrm{Sv})$ & global & $\mathrm{NH}$ & $\mathrm{SH}$ & global & $\mathrm{NH}$ & $\mathrm{SH}$ & global & $\mathrm{NH}$ & $\mathrm{SH}$ \\
\hline LIG-ctl & 12.8 & 14.77 & 15.57 & 13.98 & 8.76 & 6.53 & 10.98 & 21.00 & 24.78 & 17.22 \\
LIG- $\times$ 0.5 & 13.3 & 15.13 & 16.03 & 14.22 & 9.19 & 7.12 & 11.25 & 21.25 & 25.09 & 17.41 \\
LIG-1300m & 14.8 & 15.07 & 15.95 & 14.18 & 9.14 & 7.05 & 11.22 & 21.17 & 24.96 & 17.39 \\
LIG-1300m-alb & 15.0 & 15.14 & 16.00 & 14.29 & 9.24 & 7.10 & 11.37 & 21.24 & 25.02 & 17.46 \\
LIG-1300m-alb-CH & 14.4 & 15.32 & 16.34 & 14.29 & 9.40 & 7.49 & 11.31 & 21.43 & 25.35 & 17.50 \\
LIG-GHG & 12.8 & 14.65 & 15.50 & 13.80 & 8.69 & 6.56 & 10.82 & 20.82 & 24.64 & 17.00 \\
LIG-125k & 14.8 & 15.19 & 16.11 & 14.27 & 9.46 & 7.74 & 11.17 & 21.20 & 24.94 & 17.46 \\
PI & 16.3 & 14.51 & 15.35 & 13.67 & 8.84 & 7.44 & 10.23 & 20.09 & 22.84 & 17.33 \\
\hline
\end{tabular}

LIG-1300m (Fig. 2a, b), south-west of Greenland in LIG$1300 \mathrm{~m}$ (Fig. 2b), and a cooling of up to $-2.30^{\circ} \mathrm{C}$ over the Sea of Okhotsk (western Pacific Ocean) in LIG-1300m-alb caused by a reduction in albedo in the prescribed ice-free areas (Fig. 2c, d). In the latter simulation, the Barents Sea cooling is counteracted by a warming caused by changes in albedo (Fig. 2d).
At $130 \mathrm{kyr} \mathrm{BP}$, the $\mathrm{AMOC}$ was reduced by $3.5 \mathrm{~Sv}$ as compared to the PI (Table 2). However, a reduction in the GIS partly counteracts the negative anomaly and leads to a smaller reduction of AMOC $(3.5-2.2=1.3 \mathrm{~Sv})$ relative to the PI (Table 2). After performing an independent two-tailed Student's $t$ test with $95 \%$ confidence interval, we find that these changes in AMOC are statistically significant. 


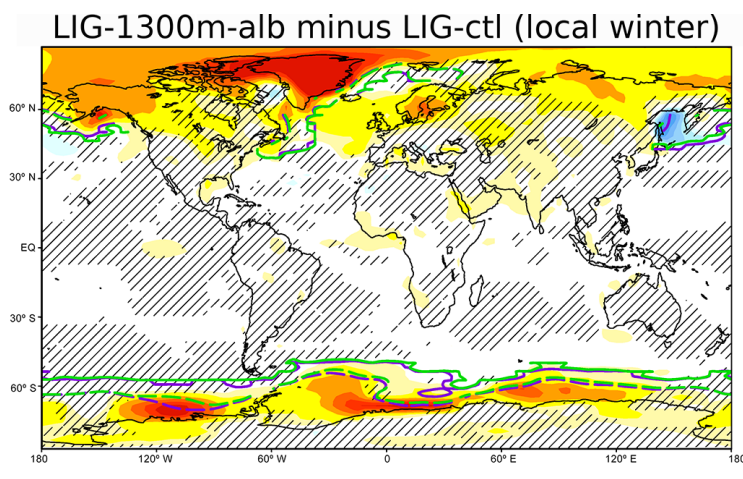

(a)

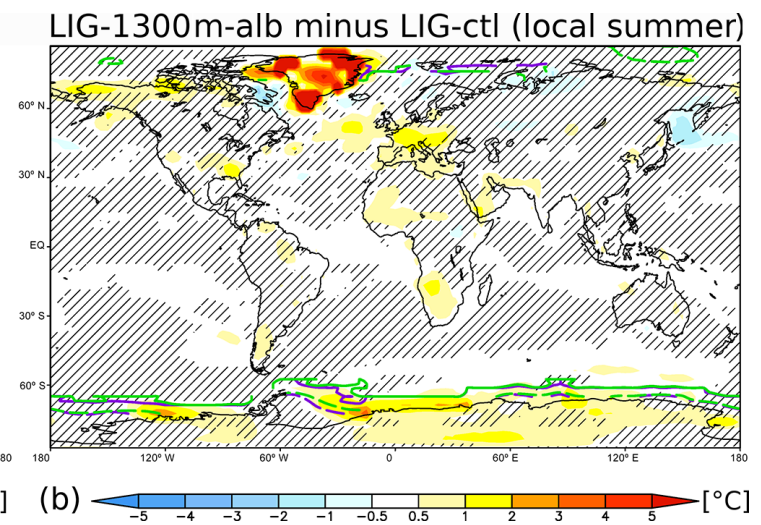

Figure 3. Effect of Greenland Ice Sheet elevation and albedo on surface temperature in the $130 \mathrm{kyr}$ BP simulation (LIG-1300m-alb). Same as Fig. 2c but for (a) local winter mean (coldest month) and (b) local summer mean (warmest month). Violet dashed lines represent the LIG-1300m-alb 50\% compactness sea ice isoline, while violet continuous lines represent the LIG-1300m-alb sea ice edge. Green dashed lines represent the LIG-ctl $50 \%$ compactness sea ice isoline, while green continuous lines represent the LIG-ctl sea ice edge.

\subsubsection{Winter and summer mean anomalies}

The seasonal effect of a reduced GIS elevation is strongest during local winter in both hemispheres in all GIS sensitivity simulations (Table 2). However, for simplicity we focus here only on the GIS sensitivity simulation that includes changes in GIS elevation and corresponding changes in albedo (LIG1300m-alb, Fig. 3). In the Northern (Southern) Hemisphere, winter TS changes by $\Delta \mathrm{TS}=+0.57^{\circ} \mathrm{C}\left(\Delta \mathrm{TS}=+0.39^{\circ} \mathrm{C}\right)$, with the northern high latitudes $\left(60-90^{\circ} \mathrm{N}\right)$ experiencing the highest positive anomalies of $\Delta \mathrm{TS}=+2.08^{\circ} \mathrm{C}$ (Fig. 3a, Table 2).

During summer, the TS anomaly is also positive but of lower magnitude, with an average of $\Delta \mathrm{TS}=+0.24^{\circ} \mathrm{C}$ for the Northern Hemisphere, Southern Hemisphere, and globally (Fig. 3b, Table 2). The northern high latitudes warm during summer by $\Delta \mathrm{TS}=+0.46^{\circ} \mathrm{C}$, which is a modest change compared to winter warming. Relatively strong cooling occurs over the Sea of Okhotsk and south-west of Greenland (Fig. 3), again with the strongest effect being present during winter.

\subsection{Combined effects of LIG forcings on global surface temperature}

The combined effects on TS of reducing the GIS by $1300 \mathrm{~m}$, adjusting albedo, and applying astronomical changes that represent an LIG climatic setting are presented in Fig. 4. Assuming linearity of the different climatic drivers, we can additionally split the anomaly of PI and LIG-1300m-alb- $\mathrm{CH}_{4}$ (equivalent to LIG-1300m-alb, but with a $\mathrm{CH}_{4}$ concentration adjusted to PI simulation) into the isolated contributions of changes in elevation and albedo and in astronomical forcing (calculated as the difference between the anomaly of LIG$1300 \mathrm{~m}-\mathrm{alb}-\mathrm{CH}_{4}$ and PI, and the anomaly of LIG-1300m-alb and LIG-ctl).
Considering the TS values from Table 2, we find that the magnitude of the astronomical forcing influence is stronger than the effects of lowering the GIS and respective adjustment of the albedo in the global average of annual mean TS, as well as the annual mean average over the Northern Hemisphere (Fig. 4a). In the Southern Hemisphere, both forcings have equal contributions to changes in annual mean TS (Fig. 4a). During winter, changes in the GIS have the strongest influence globally and in the Northern Hemisphere, while in the Southern Hemisphere changes in astronomical forcing are dominant (Fig. 4b). During summer, there is an opposite pattern (Fig. 4c). The strongest combined effect of insolation and changes in the GIS and albedo occurs in the Northern Hemisphere during summer, with an anomaly of $\Delta \mathrm{TS}=+2.51^{\circ} \mathrm{C}$. Globally, the combined effect leads to a warming of $\Delta \mathrm{TS}=+1.34^{\circ} \mathrm{C}$ during summer. In the Southern Hemisphere, the strongest combined effect is simulated during winter with $\Delta \mathrm{TS}=+1.08^{\circ} \mathrm{C}$.

The winter (local minimum TS) of the LIG is in general cooler than the PI at northern low to middle latitudes, while at northern high latitudes and Southern Hemisphere winter is warmer (Fig. 4b). If we separate the astronomical effect from the GIS lowering and albedo changes, we can attribute to insolation a cooling of $\Delta \mathrm{TS}=-0.52{ }^{\circ} \mathrm{C}$ in the Northern Hemisphere, and a warming of $\Delta \mathrm{TS}=+0.69^{\circ} \mathrm{C}$ in the Southern Hemisphere.

Summer (local maximum TS) anomalies of the LIG with respect to PI are stronger than winter anomalies in the Northern Hemisphere (Fig. 4c). Strongest continental summer TS anomalies are located in the Northern Hemisphere (up to $\Delta \mathrm{TS}=+16.7^{\circ} \mathrm{C}$ ). Locations where the LIG is cooler than PI are found at $\sim 10^{\circ} \mathrm{N}$ over Africa and at $\sim 25^{\circ} \mathrm{N}$ over India. 


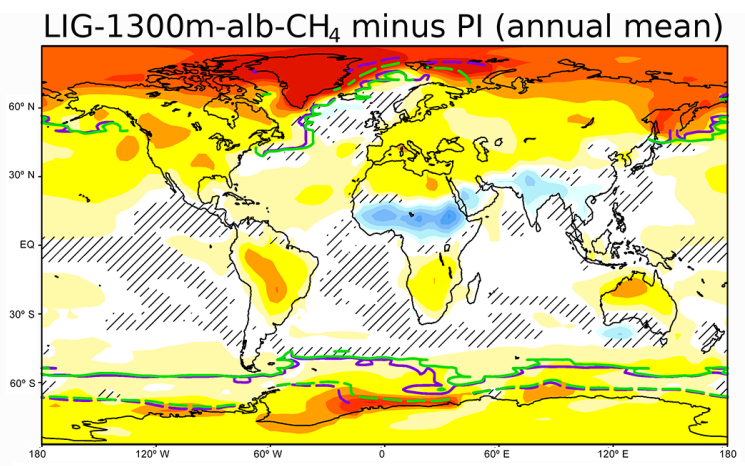

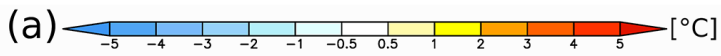

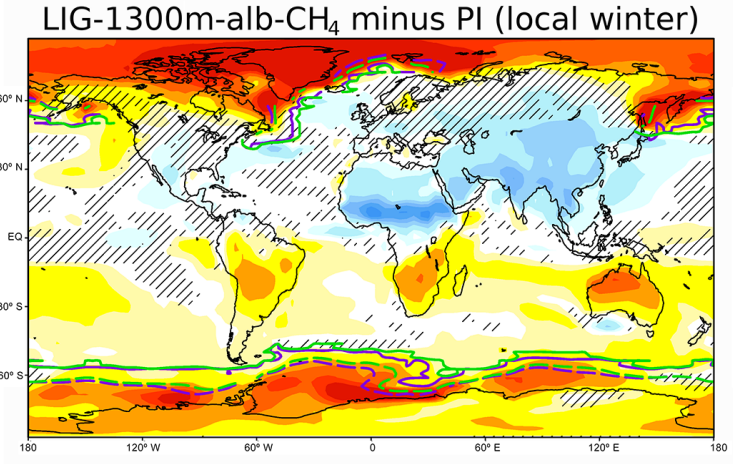

(b)
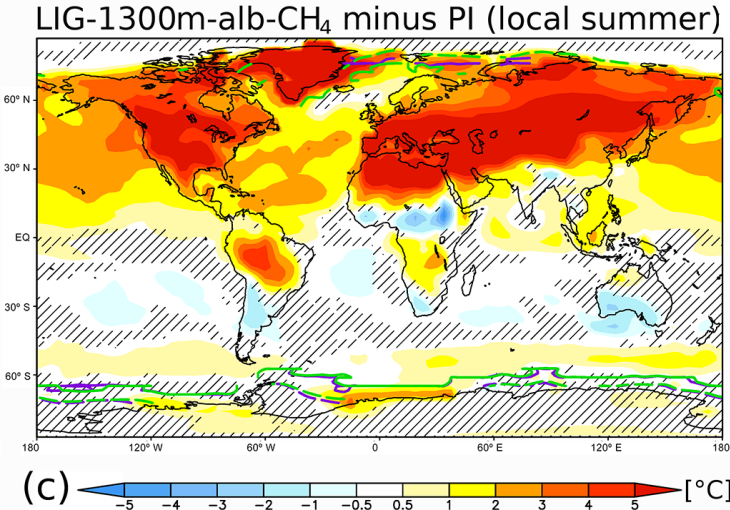

Figure 4. Effect of Greenland Ice Sheet elevation, insolation, and albedo at $130 \mathrm{kyr}$ BP relative to pre-industrial (PI). Surface temperature (TS) anomalies between LIG-1300m-alb- $\mathrm{CH}_{4}$ and PI for (a) annual mean, (b) local winter mean (coldest month), and (c) local summer mean (warmest month). Violet dashed lines represent the LIG $50 \%$ compactness sea ice isoline, while violet continuous lines represent the LIG sea ice edge. Green dashed lines represent the PI 50\% compactness sea ice isoline, while green continuous lines represent the PI sea ice edge. Hatched areas mark statistically insignificant TS anomalies.

\subsection{Surface temperature evolution during the present and Last Interglacial}

In Figs. 5, S2, and S3, a comparison of transient TS derived from the five transient simulations (Table 1) is shown. The LIG transient simulations are important for determining when the maximum LIG warmth occurred as a function of the location as well as seasons. The TS evolution in the northern high latitudes $\left(60-90^{\circ} \mathrm{N}\right)$ is displayed in Fig. 5. All LIG (130-115 kyr BP) simulations (LIG-ctl-tr, LIG- $\times$ 0.5-tr, LIG-1300m-alb-tr, and LIG-GHG-tr) indicate a similar annual mean trend, starting with a plateau until midLIG (around $123 \mathrm{kyr}$ BP) followed by a pronounced cooling trend (Fig. 5a). The LIG-ctl-tr starts at a slightly higher TS than the LIG-GHG-tr, but although the trace gas concentrations are mostly lower throughout the latter, the LIG-GHG-tr simulates higher TS throughout the LIG. This indicates that changes in the vegetation which are simulated in the LIG-ctltr lead to a cooling in the Northern Hemisphere, partly counteracting the warming induced by higher GHG concentrations. The most extreme case is represented by LIG- $1300 \mathrm{~m}-$ alb-tr, which shows predominantly the highest TS relative to
TS of other LIG transient simulations. The Holocene (8$0 \mathrm{kyr}$ BP) transient simulation (HOL-tr) also starts with a warming until around the mid-Holocene (6 kyr BP), followed by a cooling trend.

During winter, all LIG simulations indicate a positive trend in the early LIG, with maximum TS at around mid-LIG (Fig. 5b), followed by a strong cooling. The relative order of magnitudes of TS trends during different simulations is the same as for annual mean TS, but with a relatively larger offset in between simulations. Simulation HOL-tr shows a warming, followed by a cooling trend that starts at the midHolocene (Fig. 5b). Winter TS is characterized by stronger temporal variability than summer TS (Fig. 5 b, c). Summer TS in all LIG simulations indicates a slight warming trend until around 128 to $126 \mathrm{kyr} \mathrm{BP}$, followed by a pronounced cooling. The offset between transient TS is smaller than for annual mean and winter, but with the same order on the temperature scale. A dramatic cooling is also present in the Holocene simulation starting at the mid-Holocene (Fig. 5c). Furthermore, the timing of the maximum LIG warmth does not occur simultaneously between the winter and summer 


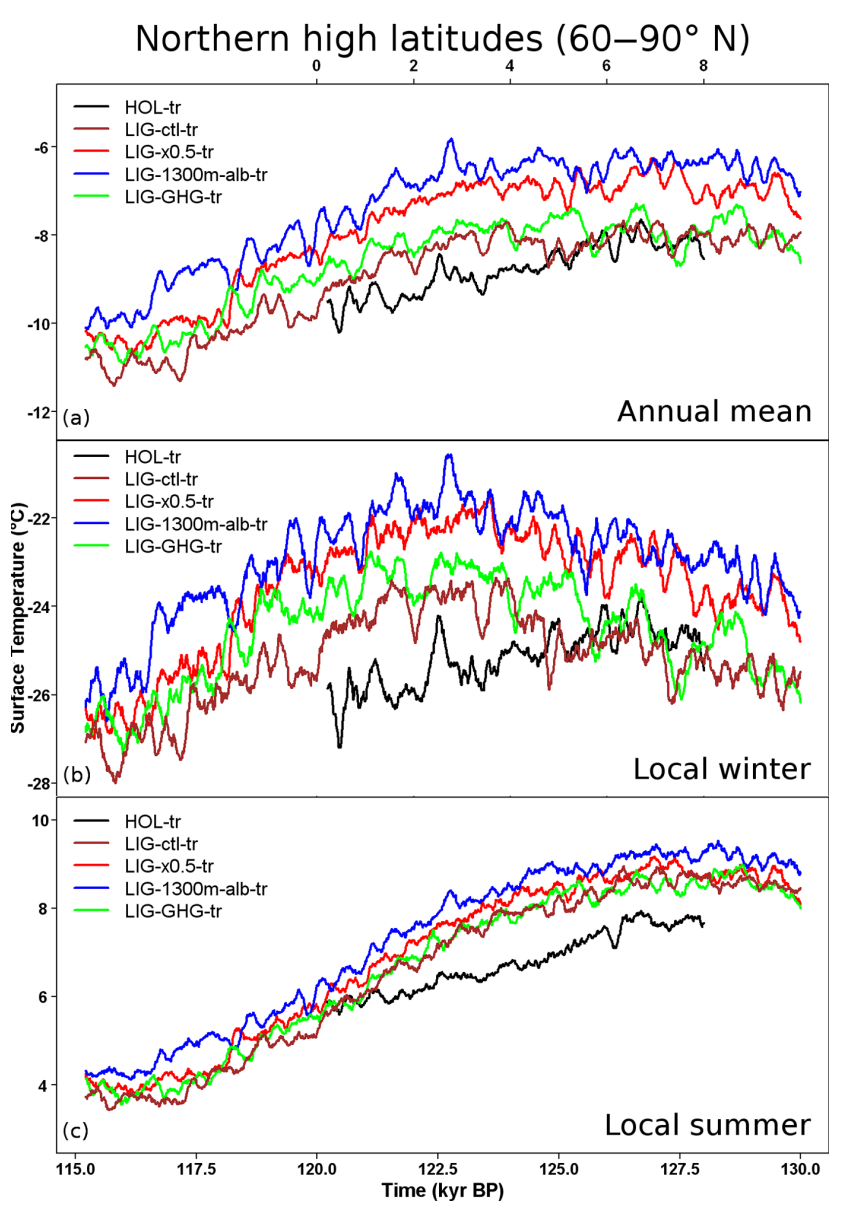

Figure 5. Simulated surface temperature evolution for the Last Interglacial (LIG-_) and the Holocene (8-0 kyr BP, HOL-tr) in northern high latitudes $\left(60-90^{\circ} \mathrm{N}\right)$ calculated as a running average with a window length of 21 model years representing 210 calendar years for (a) annual mean, (b) local winter mean (coldest month), and (c) local summer mean (warmest month). The lower $x$ scale represents the LIG timescale, while the upper $x$ scale indicates the Holocene timescale. The upper $x$ scale is matched to the timescale between 128 and $120 \mathrm{kyr} \mathrm{BP}$, assuming that Termination I and Termination II are similar with respect to obliquity (Drysdale et al., 2009).

seasons, with the winter season indicating a later peak than summer (Figs. 5, S2, and S3).

\subsection{Comparison of model results to temperature reconstructions}

Due to the large amount of simulated data, in the modeldata comparison we display simulated LIG TS derived from only one equilibrium simulation with changes in the GIS, namely LIG-1300m-alb. For the calculation of the maximum LIG warmth, we consider the corresponding transient simulation (LIG-1300m-alb-tr). However, the comparison of the proxy-based temperatures with the other GIS sensitivity sim- ulations is considered in Tables S1, S2, and S3 in the Supplement, which give the RMSD values between temperature reconstructions and simulated TS extracted at the location of each given proxy record and derived from simulations with different GIS boundary conditions. Furthermore, we display also results from control simulation for $130 \mathrm{kyr} \mathrm{BP}$ (LIG-ctl) and the corresponding transient simulation (LIG-ctl-tr) for maximum LIG warmth, in order to determine if and where GIS changes lead to an increase in model-data agreement.

\subsubsection{Proxy-based summer temperature reconstructions}

Figures 6, 8a, and S4a present a model-data comparison that consider LIG terrestrial and marine proxy-based summer temperature anomalies relative to PI derived by CAPE-Last Interglacial Project Members (2006). Simulated and reconstructed temperature anomalies agree reasonably well with respect to the sign of the change in the simulation with a reduction in the GIS (LIG-1300m-alb, Fig. 6a) and with pre-industrial GIS configuration (LIG-ctl, Fig. 6c). The best agreement between model and proxy reconstructions occurs over northern Asia and Europe. In the North Atlantic Ocean and the Arctic Ocean, the model underestimates the magnitude of change indicated by the marine-based temperature reconstructions (Fig. 6a, c). However, a reduction in the GIS and albedo leads to slightly higher summer temperature anomalies at the location of some marine proxies in the North Atlantic Ocean, partly reducing the model-data mismatch (Fig. 6a). Over Greenland, the elevation changes lead to an overestimation of the reconstructed temperature anomalies - proxy records show anomalies of +4 to $+5^{\circ} \mathrm{C}$, while the simulated TS anomalies are above $+7^{\circ} \mathrm{C}$ (Fig. 6a). However, in the LIG-ctl, there is an underestimation of the magnitude of change indicated by the reconstructed temperatures (Fig. 6c).

In the case of the terrestrial proxies, the temperature span covers +2 to $+6{ }^{\circ} \mathrm{C}$, while the corresponding simulated anomalies cover +1 to $+11^{\circ} \mathrm{C}$. In addition to the $130 \mathrm{kyr} \mathrm{BP}$ simulation (LIG-1300m-alb), for each given core location we also consider TS anomalies relative to PI calculated at the minimum and maximum LIG summer warmth as derived from the LIG-1300m-alb-tr (Fig. 8a). In about half the cases (14 records out of 27 ), the error bars touch the $1: 1$ line, possibly indicating better agreement than when compared to summer TS anomalies at $130 \mathrm{kyr}$ BP (Fig. 8a). However, the number of unresolved records can be reduced from 13 to 11 when the terrestrial proxy-based temperature anomalies are compared to the LIG-ctl-tr (Fig. S4a). Marine-based temperature anomalies and the corresponding simulated anomalies (from LIG-1300m-alb) cover temperature spans of 0 to +3 and of $\sim 0$ to $+4{ }^{\circ} \mathrm{C}$, respectively (Fig. 8a). Seven out of 13 marine records cannot be reconciled with the simulations when considering maximum and minimum summer TS anomalies during the LIG (Figs. 8a and S4a). When the reconstructed data are compared to simulated annual mean 


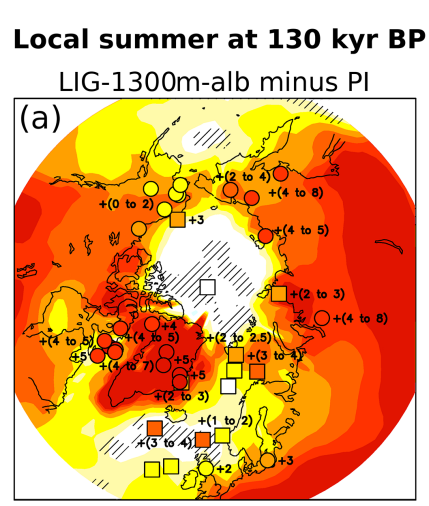

Local summer at maximum LIG warmth LIG-1300m-alb-tr minus PI

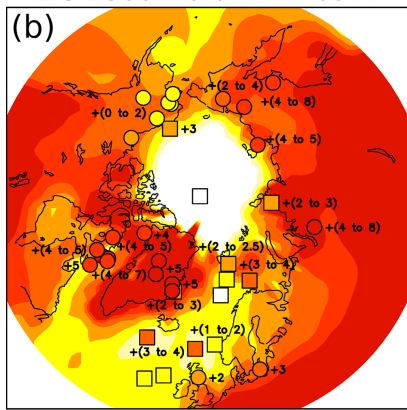

LIG-ctl minus PI

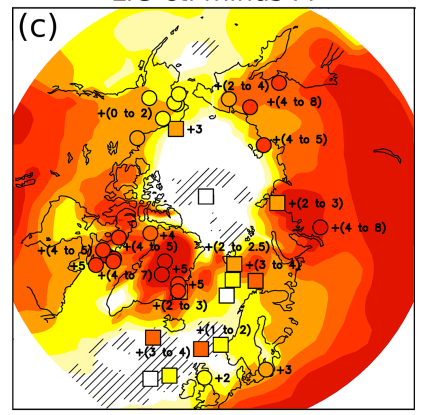

LIG-ctl-tr minus PI
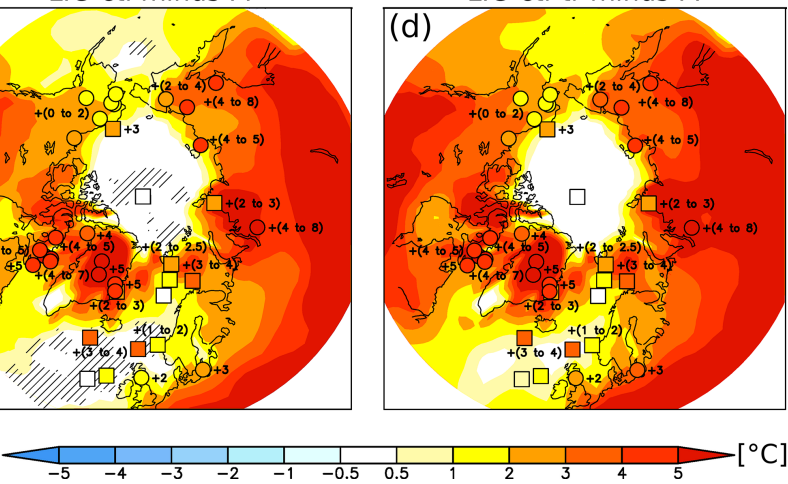

Figure 6. Effect of (a, b) Greenland Ice Sheet elevation, insolation, albedo, and atmospheric methane concentration and (c, d) insolation and atmospheric methane concentration for the Last Interglacial (LIG) relative to pre-industrial (PI). Model-data comparison of mean local summer temperature anomalies. The shading represents the simulated surface temperature (TS) anomalies at (a, c) 130 kyr BP derived from (a) LIG-1300m-alb and (c) LIG-ctl, and (b, d) summer maximum LIG warmth (warmest 100 warmest months between 130 and $120 \mathrm{kyr}$ BP) derived from (b) LIG-1300malb-tr and (d) LIG-ctl-tr, relative to PI. Hatched areas in (a, c) mark statistically insignificant TS anomalies. The squares and circles show marine and terrestrial proxy-based maximum LIG summer temperature anomalies relative to PI derived by CAPE-Last Interglacial Project Members (2006). The colours inside the squares and circles represent the proxy-based temperature anomalies derived from the intervals provided by CAPE-Last Interglacial Project Members (2006), that agree best with the simulated TS anomalies at the location of the proxies.

TS anomalies at $130 \mathrm{kyr}$ BP (Figs. S5a, c and S6) and at annual mean minimum or maximum LIG warmth (Figs. S5b, d and S6), we find an even higher discrepancy than when compared to the summer average, implying that the reconstructed records are indeed biased towards summer when assuming that the model is realistic.

The proxy data set by CAPE-Last Interglacial Project Members (2006) is considered to represent summer temperatures at the maximum LIG warmth. Thus, in the model-data comparison we additionally include the simulated maximum LIG warmth calculated from our transient LIG simulations
(Fig. 6b, d). We find that the agreement between model and data increases in some cases. For the northern North Atlantic Ocean, for example, marine records agree best with simulated TS anomalies at the maximum LIG warmth (between 121.5 and 124.5 kyr BP, Fig. 9a) in LIG-1300m-alb (Fig. 6b). However, the RMSD between the simulated TS and reconstructed temperature anomalies reveals that the best agreement occurs with TS anomalies at maximum LIG warmth in the LIG-ctl-tr (Table S1). A reduction in the GIS thus does not in general improve the model-data agreement when the data set by CAPE-Last Interglacial Project Members (2006) is considered. However, changes in the GIS lead to high temperature anomalies during local winter (Fig. 3a), while summer season is not strongly influenced (Fig. 3b). Therefore, in a comparison with proxy reconstructions that represent summer temperature anomalies, changes in the GIS do not have a significant impact on model-data agreement.

\subsubsection{Proxy-based annual mean temperature reconstructions}

Both reconstructed (Turney and Jones, 2010) and simulated global annual mean temperature anomalies indicate that the high latitudes experienced warmer temperatures during the LIG than in the PI, with strongest anomalies being present in the northern high latitudes (Fig. 7). However, the model underestimates the strong positive anomalies derived from proxy records, and in low and middle latitudes the model cannot capture the magnitude of the cooling that the proxy records show (Figs. 7a, c, 8b, and S4b).

Changes in the GIS have no significant influence in low to middle latitudes but cause strong positive anomalies in the northern high latitudes, thus improving the model-data comparison (Fig. 7a, Table S2), although the model still underestimates the amplitude of the signal depicted by reconstructions. Terrestrial proxy records indicate stronger anomalies with $\Delta \mathrm{TS}=+2.21^{\circ} \mathrm{C}$ (globally), $\Delta \mathrm{TS}=+2.21^{\circ} \mathrm{C}$ (Northern Hemisphere), and $\Delta \mathrm{TS}=+2.11^{\circ} \mathrm{C}$ (Southern Hemisphere). The corresponding simulated anomalies indicate a global average of $\Delta \mathrm{TS}=+1.44^{\circ} \mathrm{C}$, underestimating the temperature change indicated by the records by $\sim 1^{\circ} \mathrm{C}$. The Northern Hemisphere and Southern Hemisphere average TS anomalies are $\Delta \mathrm{TS}=+1.48^{\circ} \mathrm{C}$ and $\Delta \mathrm{TS}=+0.92^{\circ} \mathrm{C}$, respectively. Marine records capture lower anomalies than their terrestrial counterparts but still larger anomalies than the corresponding simulated anomalies.

The majority of the terrestrial records shows a stronger signal than the simulated anomalies (Fig. 8b). The temperature anomaly range in the terrestrial reconstructed data covers -5 to $+15^{\circ} \mathrm{C}$, while the model covers 0 to $+12{ }^{\circ} \mathrm{C}$. Out of 100 terrestrial records, 33 agree with the simulated TS anomalies somewhere between the annual mean minimum and maximum LIG warmth derived from LIG-1300m-alb-tr (Fig. 8b), and 19 records with simulated TS anomalies derived from LIG-ctl-tr (Fig S4b). 
Annual mean at $130 \mathrm{kyr} B P$

LIG-1300m-alb minus PI

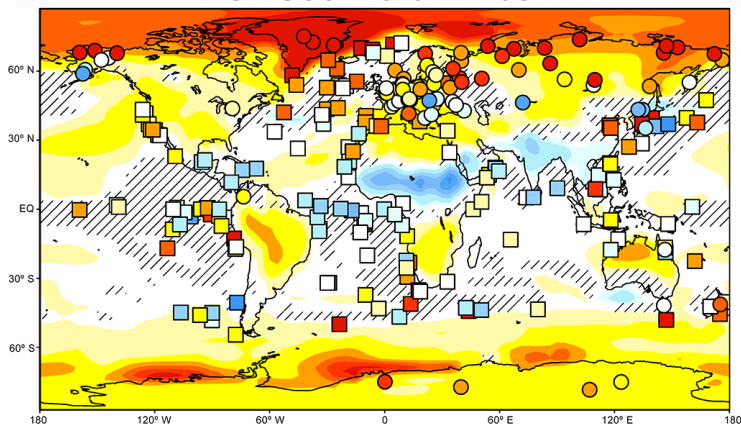

(a)

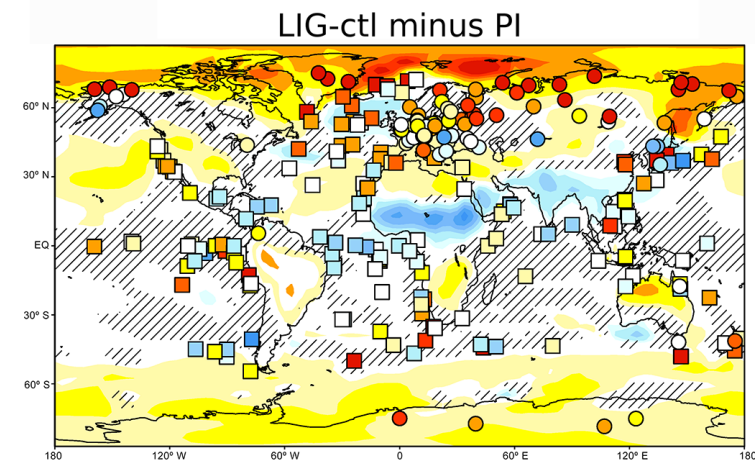

(c)
Annual mean at maximum LIG warmth

LIG-1300m-alb-tr minus PI

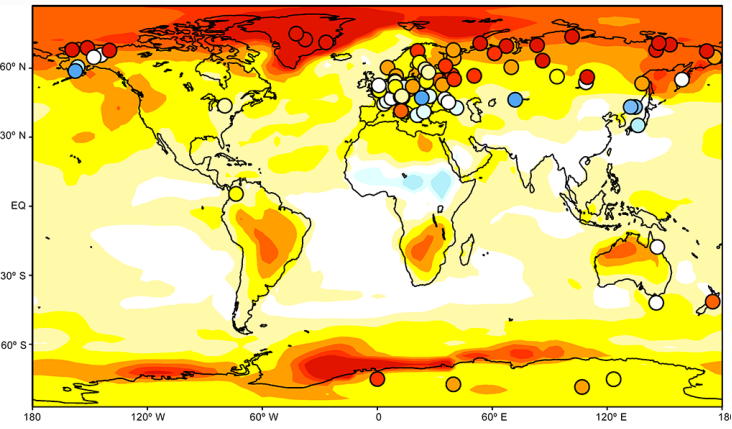

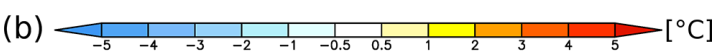

LIG-ctl-tr minus PI

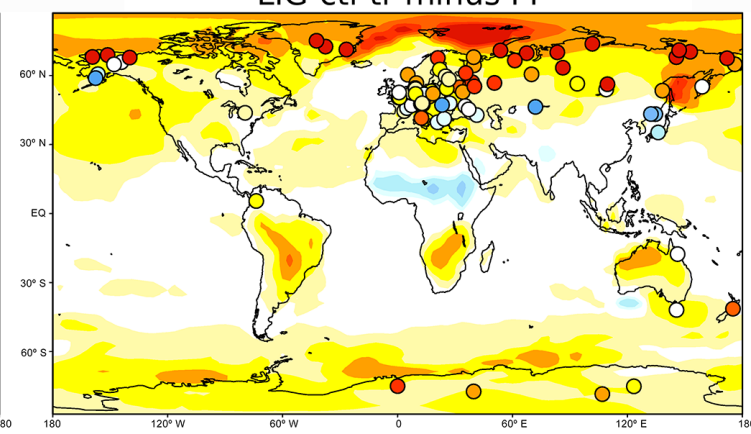

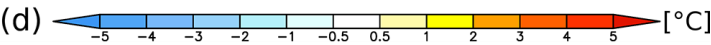

Figure 7. Effect of (a, b) Greenland Ice Sheet elevation, insolation, albedo, and atmospheric methane concentration and (c, d) insolation and atmospheric methane concentration for the Last Interglacial (LIG) relative to pre-industrial (PI). Model-data comparison of mean annual temperature anomalies. The shading represents the simulated surface temperature (TS) anomalies at (a, c) $130 \mathrm{kyr}$ BP derived from (a) LIG1300m-alb and (c) LIG-ctl, and (b, d) maximum LIG warmth (warmest 100 model years between 130 and 120 kyr BP) derived from (b) LIG1300m-alb-tr and (d) LIG-ctl-tr, relative to PI. Hatched areas in (a, c) mark statistically insignificant TS anomalies. The squares and circles show marine and terrestrial proxy-based LIG annual mean temperature anomalies relative to present day (1961-1990) derived by Turney and Jones (2010).

The reconstructed marine temperature anomalies cover a range of -6 to $+11^{\circ} \mathrm{C}$ compared to 0 to $+3{ }^{\circ} \mathrm{C}$ in the model, indicating pronounced underestimation of the marine proxybased anomalies by the model (Figs. 7a and $8 \mathrm{~b}$ ). When we consider both annual mean minimum and maximum LIG warmth, the simulated TS span increases by $\sim 1{ }^{\circ} \mathrm{C}(-0.5$ to $+3.5^{\circ} \mathrm{C}$ ). Twenty records (out of 162) agree with the model data somewhere between the minimum and maximum LIG warmth with respect to annual mean derived from LIG1300m-alb-tr, and 25 records when LIG-ctl-tr is considered (Fig. S4b).

The proxy records derived by Turney and Jones (2010) are considered to record an annual mean temperature signal. Nevertheless, some records may be biased towards a specific season. Therefore, we also consider the minimum winter and maximum summer TS during the LIG (Fig. 8c). Seasonality increases the span of the vertical bars, providing the possibility of a better agreement with the reconstructed temperature anomalies. The agreement between proxy records and model simulations increases, with 51 (69) terrestrial and 53 (51) marine records being reconciled by considering seasonality derived from LIG-1300m-alb-tr (LIG-ctl-tr) (Figs. 8c and $\mathrm{S} 4 \mathrm{c}$ ).

As already mentioned, the terrestrial proxy records by Turney and Jones (2010) are considered to record annual mean temperature anomalies at the maximum LIG warmth. Therefore, we additionally compare the terrestrial records with the simulated annual mean at the LIG thermal maximum (Fig. 7b, d). Over Europe, the agreement between model and data is increased for those records that indicate a warming, since the simulated anomalies derived from LIG-1300m-albtr indicate a warming at the maximum LIG warmth, while presenting nearly no change at $130 \mathrm{kyr}$ BP (Fig. 7a). A better agreement is also found over northern Asia. According to Table S2, the terrestrial proxy-based temperature anomalies indicate the best agreement with the simulated annual mean TS at the maximum LIG warmth derived from the LIG$1300 \mathrm{~m}$-alb-tr. The annual mean anomalies are influenced by 

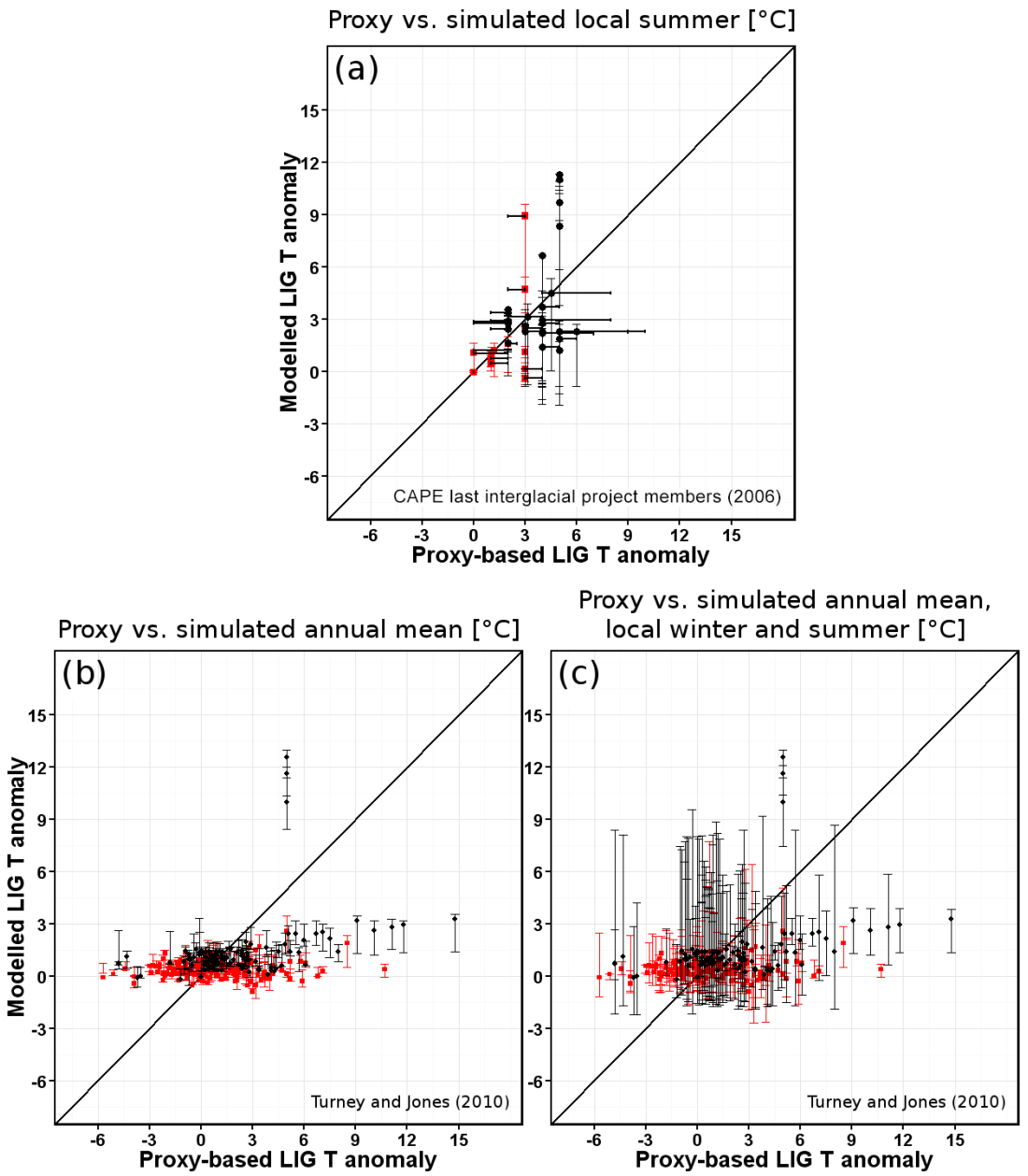

Figure 8. Effect of Greenland Ice Sheet elevation, insolation, albedo, and atmospheric methane concentration for the Last Interglacial (LIG) relative to pre-industrial (PI). (a) Proxy-based maximum LIG summer temperature anomalies relative to PI derived by CAPE-Last Interglacial Project Members (2006) plotted against simulated local summer surface temperature (TS) anomalies at 130 kyr BP (LIG-1300m-alb) relative to PI at the location of the proxies. The horizontal bars represent the proxy-based temperature intervals derived by CAPE-Last Interglacial Project Members (2006). The vertical bars indicate the simulated TS anomalies at the maximum and minimum LIG TS with respect to local summer (i.e. the coldest and warmest 100 warmest months) derived from the time interval 130 to $120 \mathrm{kyr}$ BP (LIG-1300m-alb-tr) relative to PI, for each given proxy record location. (b) Proxy-based LIG annual mean temperature anomalies relative to present day (1961-1990) derived by Turney and Jones (2010), plotted against simulated annual mean TS anomalies at $130 \mathrm{kyr}$ BP (LIG-1300m-alb) relative to PI at the location of the proxies. The vertical bars indicate the simulated TS anomalies at the maximum and minimum LIG TS with respect to annual mean (i.e the coldest and warmest 100 model years) derived from the time interval 130 to $120 \mathrm{kyr}$ BP (LIG-1300m-alb-tr) relative to PI, for each given proxy record location. (c) Same as (b) but displaying vertical bars that represent local summer and local winter mean (i.e. the warmest 100 warmest months and coldest 100 coldest months). The squares (red) and circles (black) represent marine and terrestrial proxy-based temperature anomalies, respectively. The solid thick lines represent the $1: 1$ line, which indicates a perfect match of simulated and reconstructed anomalies.

winter temperatures, the season during which GIS leads to strong positive anomalies. Therefore, a model-data comparison with proxy reconstructions that represent an annual mean signal shows a better agreement than when summer proxies are considered.

\subsubsection{Time-resolved proxy-based summer temperature reconstructions}

For a more robust model-data comparison, we additionally compare our simulated TS to a compilation of highlatitude LIG temperature anomalies derived from synchronized records representing $130 \mathrm{kyr}$ BP (Figs. 10 and S12; Capron et al., 2014). The synchronization is performed by aligning marine sediment records onto the recent AICC2012 

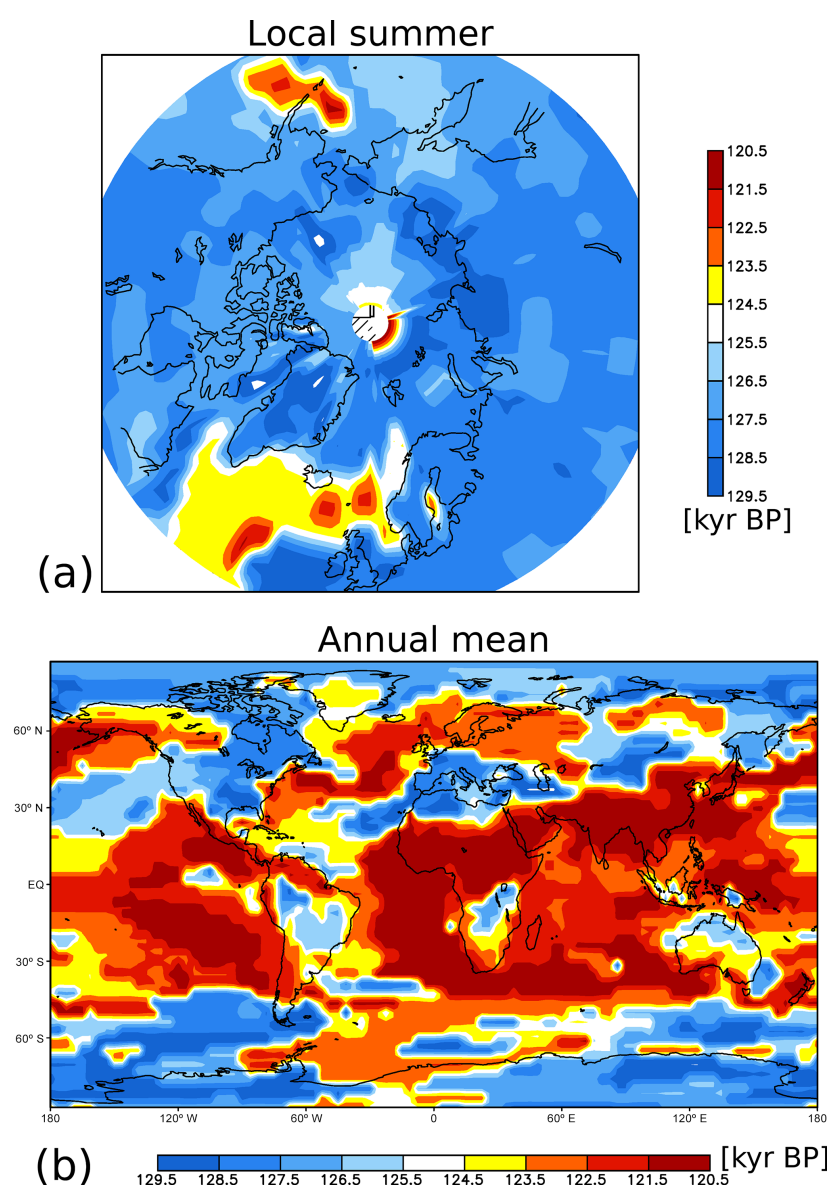

Figure 9. Timing of the maximum Last Interglacial warmth for (a) local summer (warmest 100 warmest months) and (b) annual mean (warmest 100 model years) derived from the LIG-1300m-albtr, between 130 and $120 \mathrm{kyr} \mathrm{BP}$.

ice chronology (Capron et al., 2014, and references therein). This method reduces the uncertainty in relative dating of the proxy reconstructions. The marine records from the North Atlantic Ocean indicate mostly negative anomalies, while the model simulates nearly no changes. The melting of the remnant Northern Hemisphere ice sheets from the penultimate glaciation leads to a cooling of the North Atlantic Ocean (Stone et al., 2016), a factor that is not considered in our simulations, which indicate only a modest change in this region. As shown above, GIS reduction leads to a small increase in summer TS anomalies, thus increasing the model-data disagreement (Figs. 10a and S12a). A warming in the Southern Ocean is captured by both the model and proxies, though the model underestimates the amplitude of the signal when compared to reconstructions. Reducing the GIS and albedo leads to an increase in local summer TS anomalies in the Southern Ocean, bringing the model and data into slightly closer agreement (Figs. 10b and S12a).

Considering Table S3, the reconstructed temperatures agree best with the simulated summer TS at $125 \mathrm{kyr}$ BP in
LIG-125k (Fig. S15), which considers a reduced GIS configuration (as in LIG-1300m-alb), both indicating a warming. However, this result is not conclusive with respect to the GIS elevation, as a simulation with pre-industrial GIS elevation has not been yet performed for this particular time slice. For $130 \mathrm{kyr}$ BP, the best agreement occurs for the LIG-ctl but for annual mean rather than summer, since the model simulates an annual mean cooling in the North Atlantic Ocean (Fig. S5c).

A model-data comparison of LIG temperature trends is also considered in our study (Figs. S13 and S14). The proxybased temperature trends by Capron et al. (2014) are compared to the temperature evolution derived from our transient simulations (LIG-ctl-tr and LIG-1300m-alb-tr), between 125 and $115 \mathrm{kyr}$ BP. Depending on the location, an underestimation or overestimation of the signal depicted by the proxy records in our simulation is again identified (Figs. S13 and S14). Changes in the GIS do not strongly influence the results, with the exception of a few locations where such changes lead to a less pronounced warming, thus reducing the mismatch.

\section{Discussion}

\subsection{Effects of insolation and Greenland Ice Sheet elevation on surface temperature}

The main focus of our study is to quantify the possible contribution of reduced GIS elevation in comparison with the contribution of insolation forcing to the climate of the LIG.

We can confirm the importance of insolation for the Northern Hemisphere, especially for the northern middle to high latitudes (Figs. 4, 6, 7, 10). The belt of decreased TS, observed around $10^{\circ} \mathrm{N}$ over Africa and $25^{\circ} \mathrm{N}$ over the Arabian Peninsula and India (Figs. $4 a, b$ and $7 \mathrm{a}, \mathrm{c}$ ), is related to increased cloud cover (Fig. S9) and increased summer precipitation of up to $+6 \mathrm{~mm} \mathrm{~d}^{-1}$ (not shown). This effect has been described by Herold and Lohmann (2009), who propose a mechanism for the temperature anomalies that relies on changes in insolation in conjunction with increased cloud cover and increased evaporative cooling.

In general, and independent of GIS elevation, we observe an annual mean global warming of $\Delta \mathrm{TS}=+0.44^{\circ} \mathrm{C}$ in our LIG simulations relative to PI, pointing to positive feedbacks (such as sea ice-albedo) that amplify the high-latitude insolation signal (Fig. 4).

In Sect. 3.1.2, we have shown that the most pronounced impact of reduced GIS elevation (in LIG-1300m-alb) occurs during local winter in both hemispheres (Fig. 3a). The winter warming of up to $+3{ }^{\circ} \mathrm{C}$ over the Arctic Ocean may be linked to a decrease in sea ice and a delayed response to a warming occurring in October (not shown), which is caused by positive sea ice-albedo feedbacks. A systematic analysis of insolation-driven feedbacks (e.g. sea ice, water vapour, clouds) has been done by Masson-Delmotte et al. (2011). A 

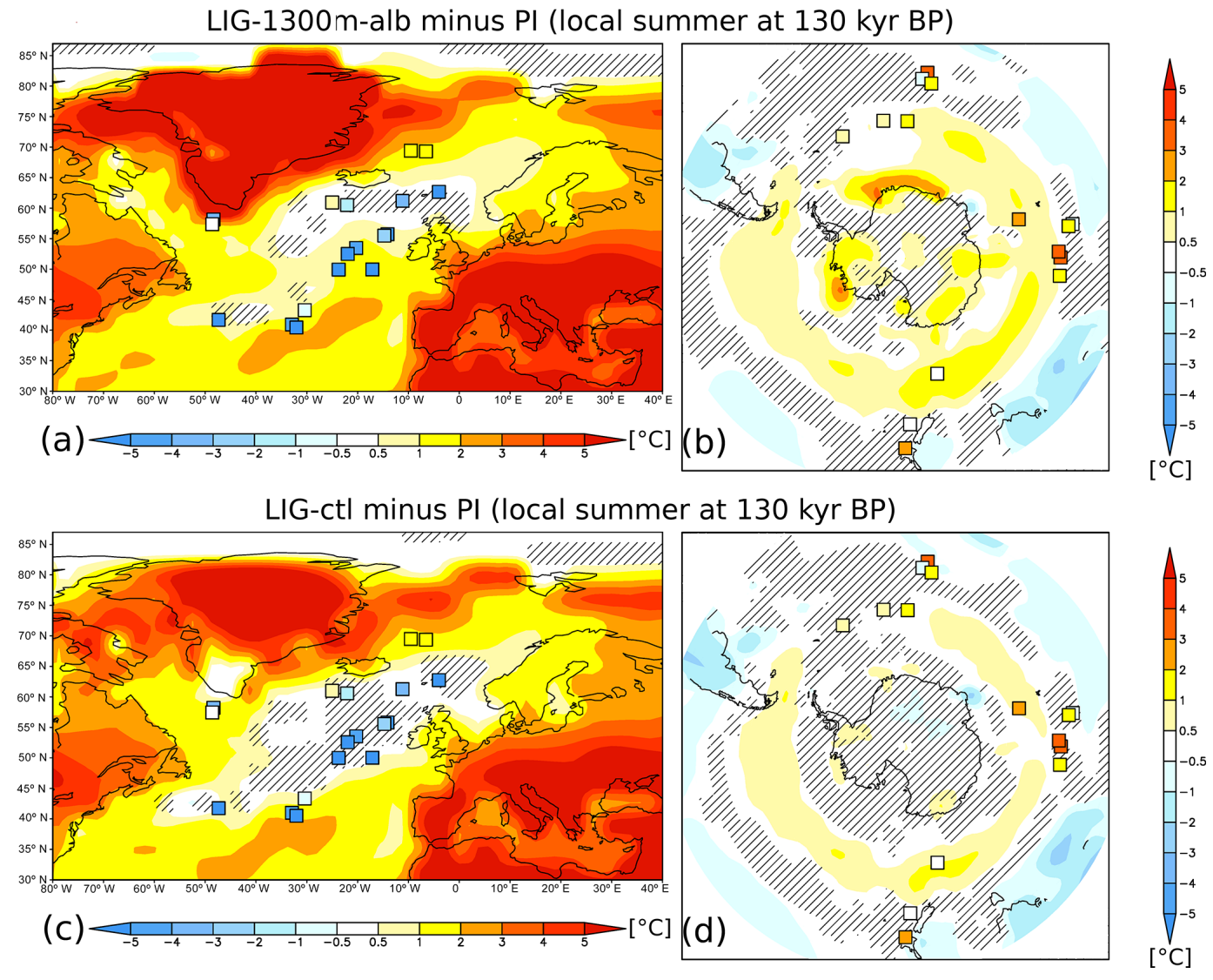

Figure 10. Effect of (a, b) Greenland Ice Sheet elevation, insolation, albedo, and atmospheric methane concentration and (c, d) insolation and atmospheric methane concentration at $130 \mathrm{kyr}$ BP relative to pre-industrial (PI). Model-data comparison of mean local summer temperature anomalies. The shading represents the simulated surface temperature (TS) anomalies derived from (a, b) LIG-1300m-alb and (c, d) LIG-ctl. Hatched areas mark statistically insignificant TS anomalies. The squares show marine proxy-based LIG (130 kyr BP) summer temperature anomalies relative to present day derived by Capron et al. (2014).

decrease in albedo over Greenland has the strongest influence during summer especially over the southernmost region (Figs. $2 \mathrm{~d}$ and $3 \mathrm{~b}$ ), caused by insolation absorption by the icefree land surface. Furthermore, we note cold annual mean anomalies in the Barents Sea (Fig. 2a, b) and Sea of Okhotsk (Fig. 2c) caused by an increase in sea ice cover.

The change in the GIS elevation also leads to a relatively strong warming in the southern high latitudes, mainly off the coast of Antarctica, with the strongest positive anomaly occurring during local winter (Fig. 3a) that coincides with a heat flux transfer anomaly from the ocean to the atmosphere (not shown). Increased ocean heat flux during winter leads to a warming of the atmosphere. The Antarctic warming is most likely related to warmer deep water as well as subsurface warming poleward of $50^{\circ} \mathrm{N}$ in the North and South Atlantic Ocean. The warming may be attributed to enhanced AMOC (Table 2), which plays an important role in the exchange of heat between the hemispheres and between atmosphere and ocean. Our results indicate a weaker AMOC during the LIG as compared to the PI of up to $3.5 \mathrm{~Sv}$, but changes in the GIS lead to an increase of up to $2.2 \mathrm{~Sv}$ (Table 2). The simulated increase in AMOC in the sensitivity simulations may be triggered by increased salinity of up to +1 psu in the northern North Atlantic Ocean. Increased salinity cannot be explained by changes in precipitation minus evaporation, which show positive anomalies in this area (not shown). Another contributing factor to the enhanced AMOC may be an increase in the atmospheric flow due to a reduction in GIS elevation. The low-pressure system over Greenland and the high pressure system above Europe become more extreme, enhancing the north-eastward air circulation (Fig. 11). We find that the higher the sea level pressure (SLP) anomaly (Fig. 11), the stronger the AMOC (Table 2). This change could also explain the positive TS anomalies of up to $+1^{\circ} \mathrm{C}$ in the northern North Atlantic Ocean, with more heat being transported poleward from the low latitudes (Fig. 2a-c). However, convection cannot be the only explanation for the southern high latitudes' warmth, since the heat would be dispersed towards the Southern Hemisphere. Nonetheless, we note a large-scale warming in the subsurface of the Southern 

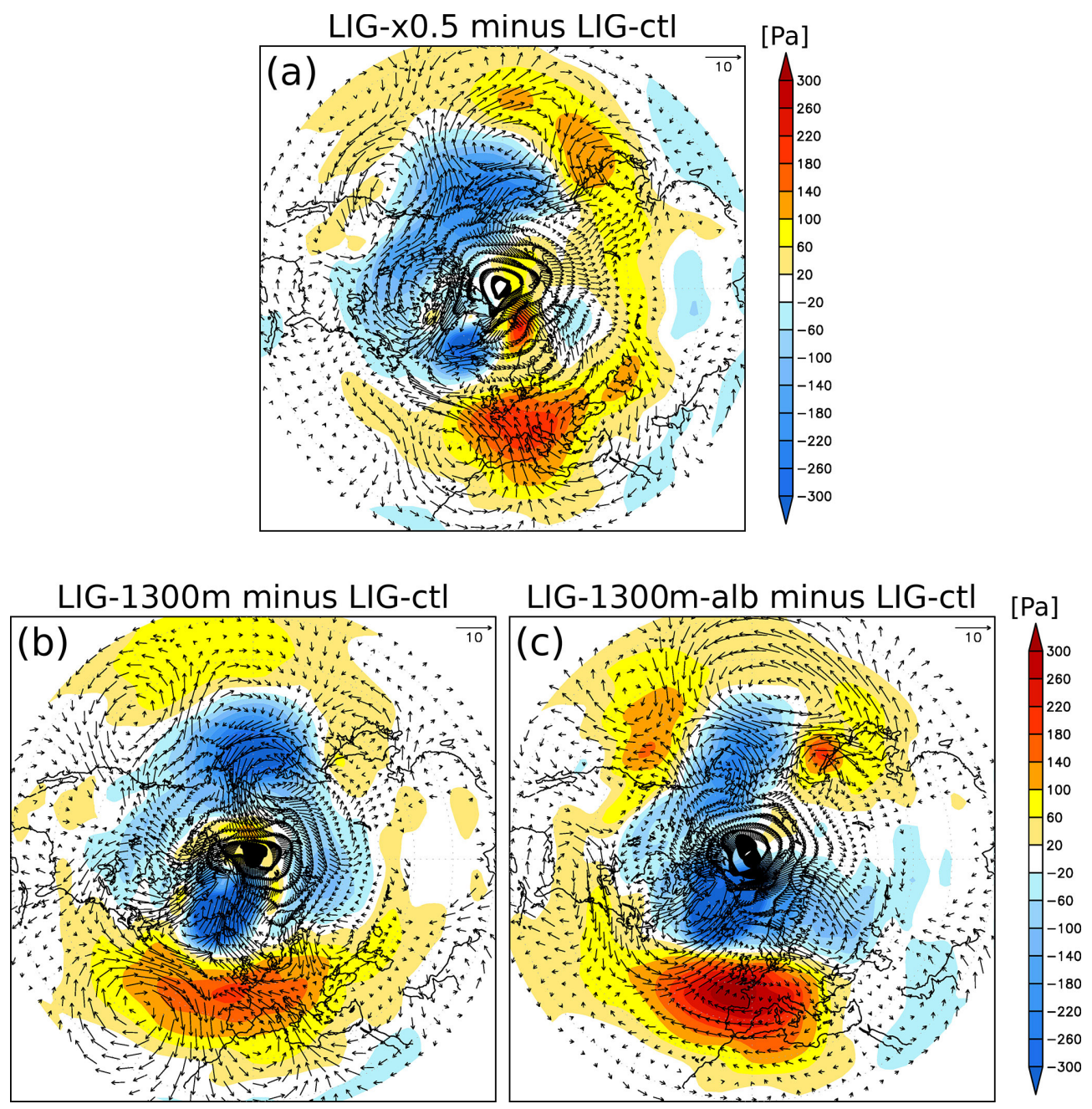

Figure 11. Effect of (a-c) Greenland Ice Sheet elevation and (c) albedo on sea level pressure (SLP) and surface winds in $130 \mathrm{kyr} B P$ simulations. The shading represents December-January-February (DJF) mean SLP anomalies, superimposed by DJF mean surface wind anomalies (in m s${ }^{-1}$ ) for (a) LIG- $\times 0.5$ minus LIG-ctl, (b) LIG-1300m minus LIG-ctl, and (c) LIG-1300m-alb minus LIG-ctl. The vector length indicates the wind speed (in $\mathrm{m} \mathrm{s}^{-1}$ ).

Ocean which is probably caused by positive feedbacks. This warming may be related to changes in the water stratification. We observe an invigorated vertical mixing in the northern North Atlantic Ocean and a suppressed vertical mixing in the Southern Ocean (not shown), the latter causing the heat at the subsurface to be preserved. The Southern Ocean has a large heat capacity, leading to a long memory of the system. Lags of up the 3 months occur in the surface layer including sea ice (amplifying factor via positive ice-albedo and iceinsulation feedbacks), while long-term lags occur in deeper levels below the summer mixed layer that store seasonal thermal anomalies (Renssen et al., 2005).

In contrast to our results that show an increase in the AMOC in response to GIS elevation changes, Otto-Bliesner et al. (2006) and Bakker et al. (2012) find a weakening of the AMOC. Bakker et al. (2012) infer that the AMOC is weaker by up to $14 \%$ in a regional study of LIG climate of the North
Atlantic Ocean, prescribing a reduction of GIS elevation (by $700 \mathrm{~m}$ ) and extent (reducing the ice volume by $30 \%$ ). The weakening of the AMOC is caused by additional freshwater runoff resulting from a melting GIS, a factor that is not considered in our study and that would probably cancel out or reduce the effect of changes in the atmospheric transport on the AMOC. In the study by Bakker et al. (2012) using a simplified atmosphere model, reducing GIS elevation and extent leads to changes in the atmospheric flow pattern and creates a special pattern of surface pressure anomalies. In particular in the Norwegian Sea, Barents Sea, and south-east of Greenland, the low-pressure system is weaker, inhibiting the overturning circulation.

The reduction of the GIS elevation and albedo alone leads in the study by Bakker et al. (2012) to a local warming of up to $+4{ }^{\circ} \mathrm{C}$ in July, a substantially lower anomaly (by a factor of $\sim 3$ ) than simulated in our model for local summer when re- 
ducing both GIS and albedo. However, when comparing their simulated data to proxy-based temperature anomalies relative to PI (CAPE-Last Interglacial Project Members, 2006), Bakker et al. (2012) find an overestimation of the magnitude of temperature change recorded by reconstructions over Greenland, and an underestimation for eastern Europe and Baffin Island - locations where we find a similar temperature tendency (Fig. 6a).

Another climate model study that considers a reduction in GIS topography by various methods has been performed by Merz et al. (2014). In their GIS sensitivity simulations, performed with the Community Climate System Model version 4 (CCSM4), they find a rather mixed signal in temperature anomalies over Greenland relative to the predominant warming found in our simulations with changes in the GIS. During local winter, their model simulates a warming of up to $+5{ }^{\circ} \mathrm{C}$ in central Greenland and a cooling of up to $-12{ }^{\circ} \mathrm{C}$ in areas that become flat and ice-free. However, changes in the topography of the GIS do not have a significant influence on climate in the surrounding areas in the study by Merz et al. (2014). This may be caused by the fact that SSTs are prescribed in their simulations, while in our study the atmosphere model is interactively coupled to an ocean general circulation model. However, in their study the GIS is reconstructed by means of high-resolution ice sheet models, while we consider a relatively simplistic representation of the GIS. Differences are also found with respect to changes in lowlevel winds. They find a rather local influence of the GIS changes and no major effect on the large-scale atmospheric circulation. Our model simulates an enhancement of lowlevel winds around GIS and on SLP (Fig. 11). As such, the methods of reducing GIS and the model used have a strong influence on the local- and large-scale climate. Note, however, that the aims of our study and the study by Merz et al. (2014) are different, since the latter focuses on local effects above Greenland, while our main focus is on the GIS effects on large-scale climate.

\subsection{Surface temperature evolution during the Last Interglacial and the Holocene}

Although our results are not directly comparable to those derived by Bakker et al. (2013), who analyse transient LIG January and July temperature anomalies (simulated by seven different models) with respect to PI, while we use transient absolute TS for coldest and warmest month, the pattern of the temperature evolution remains the same. We observe similarities in middle latitudes and in winter temperatures at high latitudes characterized by a large variability, and also note a clear cooling trend for summer caused by a decrease in summer insolation. At northern high latitudes, Bakker et al. (2013) find July maximum LIG warmth at 128.4-125.1 kyr BP, while in middle latitudes the maximum occurs at 129.4-126.3 kyr BP. We also observe a warmest month maximum at around $128 \mathrm{kyr} \mathrm{BP}$ for high and middle latitudes. A July maximum LIG warmth is found in the study by Loutre et al. (2014) at $128 \mathrm{kyr} \mathrm{BP}$. They find that the summer SST during the LIG is smaller in the model than in the reconstructed temperatures, especially in the North Atlantic Ocean, but taking into account the evolution of the Northern Hemisphere ice sheets reduces the disagreement between model and data.

During winter, our simulations produce a clear highlatitude TS maximum around mid-LIG, while the middle latitudes experience peak warmth around 121-117 kyr BP. Bakker et al. (2014) compare transient LIG and Holocene (80 kyr BP) temperature trends simulated by different models (including our COSMOS LIG-GHG-tr and HOL-tr simulations). They find negative warmest month temperature trends for both LIG and Holocene in the Northern Hemisphere. Bakker et al. (2013) find a linear relation between changes in insolation and temperatures for both summer and winter and for all latitudes. There are, however, some exceptions. In northern high latitudes, the winter temperature changes result mainly from sea-ice-related feedbacks and are described as highly model-dependent. In southern middle to high latitudes, winter temperatures are strongly affected by changes in GHG concentrations. Comparing all LIG transient simulations with the Holocene in the three considered latitudinal bands, we observe that the Holocene experiences mostly lower TS than during the LIG and is characterized by smaller trends.

In our LIG transient simulations, we find that the differences in TS between the different model simulations at the beginning of the LIG (130 kyr BP) are higher than during the late LIG (115 kyr BP), indicating that the impact of a reduced GIS is stronger at the beginning of the LIG as compared to glacial inception (GI, $115 \mathrm{kyr} \mathrm{BP})$, possibly related to an interplay with insolation forcing. By using different approaches to simulate the LIG evolution, we offer a spectrum of possible temperatures, in our model-data comparison, at each given time between 130 and $115 \mathrm{kyr}$ BP.

\subsection{Model-data comparison}

In combination with changes in the GIS elevation and lower albedo, the insolation effect leads to high positive summer TS anomalies in the Northern Hemisphere (Figs. 4c and 6a, c). The pattern of these changes is observed also in another model study of the LIG that includes a reduction in GIS elevation of $500 \mathrm{~m}$ (Otto-Bliesner et al., 2006). The study shows that the June-July-August (JJA) temperature anomaly with respect to PI is positive in the Northern Hemisphere, especially over the continents - yet the magnitude of these changes is smaller than in our study. In order to validate their results, Otto-Bliesner et al. (2006) compare the simulated temperature anomalies to proxy-based temperature anomalies by CAPE-Last Interglacial Project Members (2006). Comparing our model results to the same proxy compilation, we see most similarities in the local summer, although 
at some locations the magnitude differs. Over Greenland, the warming reaches $+5^{\circ} \mathrm{C}$ according to the proxy reconstructions, while our results show a higher warming caused by the reduction of the GIS. However, the results from OttoBliesner et al. (2006) indicate an underestimation. This suggests that the GIS elevation during the LIG may have not been so drastically reduced as prescribed in our model setup but was still reduced by at least $500 \mathrm{~m}$. This conclusion is supported by another model-data comparison study (Stone et al., 2013) that uses the same data compilation (CAPELast Interglacial Project Members, 2006). In their simulation produced with an AOGCM, Stone et al. (2013) find a good agreement between model and reconstruction as well but cannot capture the reconstructed strong warming over Greenland, where their simulation indicates a warming of up to $+3.5^{\circ} \mathrm{C}$. They imply that the GIS was reduced in the LIG as compared to PI, but not completely deglaciated in the simulation with a completely removed GIS, they find much stronger temperature anomalies over Greenland of up to $+16^{\circ} \mathrm{C}$, higher than in our findings when the GIS is reduced to half its present elevation (Fig. 2). A high overestimation of the magnitude of the temperature change by the model is also found by Otto-Bliesner et al. (2006) for a deglaciated Greenland, with summer temperature anomalies being higher than $+10^{\circ} \mathrm{C}$. Although in our simulations we do not completely remove the ice sheet, we find strong TS anomalies of up to $+11^{\circ} \mathrm{C}$.

A warming as high as $+8 \pm 4{ }^{\circ} \mathrm{C}$ is proposed by NEEM community members (2013) for the peak LIG warmth at 126 kyr BP, based on NEEM ice core. They propose that the north-west GIS is characterized only by a modest reduction of $400 \pm 250 \mathrm{~m}$ between 128 and $122 \mathrm{kyr}$ BP. In our study, we find at the location of the NEEM ice core an annual mean warming of $+9.6^{\circ} \mathrm{C}$ at $125 \mathrm{kyr} \mathrm{BP}$ at a GIS height of $553 \mathrm{~m}$, a warming that is within the temperature range proposed by NEEM community members (2013). When the temperature estimate from NEEM ice core is not corrected for elevation changes, it indicates a positive anomaly of $7.5 \pm 1.8^{\circ} \mathrm{C}$. Such dramatic temperature changes at the NEEM site are proposed by another recent study based on ice core air isotopic composition $\left(\delta^{15} \mathrm{~N}\right)$ and relationships between accumulation rate and temperature (Landais et al., 2016). Their study suggests anomalies between the LIG (126 kyr BP) and the PI of +7 to $+11^{\circ} \mathrm{C}$, with $+8^{\circ} \mathrm{C}$ being considered the most likely estimate. Antarctic ice cores indicate positive temperature anomalies of up to $+3.5^{\circ} \mathrm{C}$ (Capron et al., 2014), suggesting stronger warming than the simulated TS. However, a reduction in the GIS reduces the model-data disagreement. Moreover, our study does not account for possible changes in the Antarctic ice sheet topography and its potential impacts (Sutter et al., 2016, and references therein).

We go one step further and perform an additional modeldata comparison with global coverage (Turney and Jones, 2010). This proxy compilation is included in another modeldata comparison study for the LIG (Lunt et al., 2013), using a multi-model approach including the LIG-GHG. None of the model simulations used in their study consider a reduction of the GIS elevation or albedo. Lunt et al. (2013) find as well that the models fail to capture the magnitude of the temperature change suggested by the proxy data. In their study, none of the simulations manage to capture a strong highlatitude annual mean warming indicated by the terrestrial proxy data. In fact, most of the models suggest a slight cooling over Europe and northern Asia and only a slight warming over Greenland, at $130 \mathrm{kyr}$ BP. The LIG-1300m-alb indicates a relatively higher warming, reducing the disagreement between model and data. Over Antarctica, the simulated and reconstructed temperature anomalies indicate a warming of similar magnitude, in contrast to the simulations performed by Lunt et al. (2013), where most of the models indicate a slight cooling. These results imply that a reduced GIS during the LIG improves the model-data comparison. The RMSD values support this assumption (Table S2), although differences between the considered cases (i.e. with or without a reduction in the GIS) are relatively small - in the calculation of the RMSD, all the proxy records by Turney and Jones (2010) are considered, including a large number of records in the low latitudes where a change in the GIS has no influence.

In all considered simulations, the model does not capture the magnitude of the SST anomalies derived from marine records. Such an underestimation of temperature changes derived from proxy data by the models is also found in modeldata comparison studies for the Holocene (Masson-Delmotte et al., 2006; Brewer et al., 2007; Sundqvist et al., 2010; Zhang et al., 2010; O'ishi and Abe-Ouchi, 2011; Braconnot et al., 2012; Lohmann et al., 2013; Bakker et al., 2014). Lohmann et al. (2013) show that the simulated SST trends systematically underestimate the marine proxy-based temperature trends, and suggest that such discrepancies can be caused either by too simplistic interpretations of the proxy data (including dating uncertainties and seasonal biases) or by underestimated long-term feedbacks in climate models, a feature which is probably also valid for the LIG. This also calls to perform LIG simulations in Earth system models that account for feedbacks not accounted for in our simulations, such as those associated with interactive soils (Stärz et al., 2016) and interactive ice sheet model components (Barbi et al., 2014; Gierz et al., 2015). For instance, the GIS is expected to thicken at the start of an interglacial period due to enhanced accumulation associated with deglacial warming (see also NEEM community members, 2013). We did not consider this in our simulations, although potential effects of the ice sheets during the LIG exist (e.g. Sutter et al., 2016).

As shown above, the TS in low to middle latitudes experiences mostly no change in our simulation, in contrast to the proxy-based SST anomalies that indicate strong positive or negative temperature changes. Our results partly contradict results from another early LIG (130 kyr BP) model simulation (Otto-Bliesner et al., 2013). Their Community Climate System Model 3 (CCSM3) simulates mostly a cool- 
ing in the ocean, with the exception of the North Atlantic Ocean south of Greenland, where the anomalies have the same sign as proxy-based SSTs by Turney and Jones (2010). The terrestrial records located in the high latitudes indicate, however, a better agreement with the LIG-1300m-alb. Even when considering mid-LIG (125 kyr BP) in both studies (see Fig. S11 for our study), the terrestrial data can be better reconciled with the simulation in which GIS elevation and albedo are reduced, especially over Antarctica, where OttoBliesner et al. (2013) find a cooling. Nevertheless, the difference between the magnitude of change in model and reconstruction is still large. Otto-Bliesner et al. (2013) suggested that this mismatch may arise from the lack of vegetation feedback. Here, the fact that we account for the vegetation feedback challenges this explanation. Over Greenland, the CCSM3 model underestimates the amplitude of changes when compared to reconstructions, while our model simulations with reduced GIS have too large simulated changes when compared to the same reconstructions. Otto-Bliesner et al. (2013) propose that the Greenland ice records may capture temperatures associated with a reduction in GIS elevation. This suggests again that the LIG GIS was lower, but possibly not as low as prescribed in our study. Otto-Bliesner et al. (2013) also take into account possible seasonal biases considered by Lohmann et al. (2013), comparing the proxy data to simulated JJA temperature anomalies for which they find the best fit, suggesting that the proxies record boreal summer temperatures. In our study, however, we find the best overall fit for simulated annual mean rather than summer TS (Figs. S7a, c and S8) in all three cases: reduced GIS and albedo at $130 \mathrm{kyr}$ BP (LIG-1300m-alb, Figs. 7a and $8 \mathrm{~b}$ ) and at $125 \mathrm{kyr}$ BP (LIG-125k, Fig. S11a, c), and preindustrial GIS at $130 \mathrm{kyr} \mathrm{BP}$ (LIG-ctl, Figs. 7c and S4b), with the best agreement between model and data in the first case (Table S2). This could indicate that the proxies may indeed record annual mean temperatures, but in a warmer climate caused by a reduced GIS (Fig. 7a). While the simulated summer TS is closer to the proxies at some locations (e.g. northern Asia and Europe, Figs. S7a, S8), there are still more records that agree best with the simulated annual mean TS (Fig. 7a). Along with the simulated increase in TS, there is an annual mean reduction in sea ice in the simulations with reduced GIS compared to the PI (not shown).

Capron et al. (2014) had compared their data compilation to two other climate model simulations, namely CCSM3 and HadCM3. For $130 \mathrm{kyr}$ BP, a model-data mismatch is found in both cases, as most of the records indicate strong negative anomalies, while the models simulate strong positive anomalies (Capron et al., 2014), especially CCSM3, which was run with higher GHG concentrations than HadCM3 and COSMOS. With respect to the difference between model and data, COSMOS simulates TS closer to the temperatures derived from marine-based records, since it indicates nearly no change rather than a strong opposite signal. One cause of this modest change in the North Atlantic Ocean may be related to vegetation changes, which may lead to a cooling as suggested above. The vegetation feedback counteracts the warming caused by predominantly higher GHG concentrations; in the simulation with dynamic vegetation (LIG-ctl-tr), the $\mathrm{CO}_{2}$ concentration is higher by up to $15 \mathrm{ppmv}$ than in the simulation with fixed pre-industrial vegetation (LIG-GHGtr). However, higher temperatures are found for the simulation with lower GHG concentrations (LIG-GHG-tr). Another cause may be the decrease in AMOC at the LIG with respect to PI, leading to the bipolar seesaw, a pattern that is also observed in the proxy data at $130 \mathrm{kyr} \mathrm{BP}$. We note a relative cooling in both LIG simulations south of Iceland and Greenland. This region is very sensitive to changes in the AMOC as shown in observational and numerical studies (Knight et al., 2005; Latif et al., 2006; Dima and Lohmann, 2010).

For $125 \mathrm{kyr} \mathrm{BP}$, COSMOS simulates higher anomalies in the North Atlantic Ocean than at $130 \mathrm{kyr}$ BP, but lower than CCSM3 and HadCM3, which simulate SSTs closer to the reconstructed temperatures (Fig. S15a). Note, however, that the definition of summer is different in our study than in the study by Capron et al. (2014), as they calculate it as the average of July-August-September, while we consider the warmest month.

\subsection{Limitations of model-data comparison}

One challenge in an effective LIG model-data comparison is the difficulty to determine an absolute dating of LIG marine palaeo-proxy records (e.g. Drysdale et al., 2009), as few techniques exist for this purpose. The dating of most of the records is derived by lining up their benthic $\delta^{18} \mathrm{O}$ signal to a dated benthic $\delta^{18} \mathrm{O}$ stack (Lisiecki and Raymo, 2005). This strategy allows a relative dating of sediment cores beyond the time limit of radiocarbon dating (Fairbanks et al., 2005; Chiu et al., 2007; Reimer et al., 2009, 2013; Shanahan et al., 2012), but it may lead to an artificial synchronization of all records and therefore dampen regional differences in climate records with respect to the LIG chronozone. An alternative method for synchronizing different types of proxies is used in Govin et al. (2012), in which proxy records are aligned to the AICC2012 ice core chronology. Their study shows that the maximum temperature changes during the LIG are different between the two hemispheres, with the records from Southern Ocean and Antarctica showing an early maximum compared to the records from northern high latitudes. This method is used by Capron et al. (2014) in their proxy data compilation, and further applied in Govin et al. (2015), thus allowing for one less uncertainty in the model-data comparison. However, using such a time-resolved temperature compilation does not improve our model-data comparison, as when compared to the other proxy-based data sets that represent the maximum LIG warmth.

Additionally, some proxy records that are considered as recording annual mean temperatures are seasonally biased, depending on the type of the proxy or on the region (Leduc 
et al., 2010; Schneider et al., 2010; Lohmann et al., 2013). Furthermore, defining the timing of the maximum warmth during the LIG also represents a challenge. Bakker and Renssen (2014) show that the calculation of the maximum LIG temperature is largely model-dependent, indicating also geographical and time dependency (retrieved values differ between the annual mean and warmest month temperature anomalies). They propose that the time dependency originates from the dependency of the time evolution of orbital forcing on latitude and seasons, as well as from the thermal inertia of the oceans and from different feedbacks in the climate system. Our model results indicate that the timing of maximum LIG warmth is indeed regionally dependent (Fig. 9).

\section{Conclusions}

In this study, we have analysed data from several LIG sensitivity simulations performed with an AOGCM and have assessed the influence of the GIS on global climate. We have compared the simulated TS changes to anomalies as recorded by LIG climate data synthesis of CAPE-Last Interglacial Project Members (2006), Turney and Jones (2010), and Capron et al. (2014).

We have shown that the exact method by which GIS configuration is changed has a significant influence on hemispheric temperature anomalies. A reduction in the GIS by $1300 \mathrm{~m}$ and changes in albedo enhance the warming caused by changes in the astronomical forcing by up to $+5^{\circ} \mathrm{C}$. The LIG is much warmer than the PI, especially during summer in the Northern Hemisphere, and during winter in the Southern Hemisphere as well as northern high latitudes. The influence of astronomical forcing is dominant (relative to changes in the GIS) in the global and Northern Hemisphere average of annual mean and local summer TS, and in the Southern Hemisphere winter. Changes in the GIS have the strongest influence (relative to insolation changes) in the global and Northern Hemisphere average of local winter TS, and in the Southern Hemisphere summer.

Modification of the GIS alone leads to a warming mostly in the northern and southern high latitudes. Cooling occurs locally in Barents Sea or Sea of Okhotsk (depending on the simulation). The warming caused by a reduced GIS has a winter rather than a summer signal at both hemispheres.

The simulated TS underestimates the temperature changes indicated by the proxy reconstructions. However, a reduction in GIS elevation and extent improves the agreement between model and data by Turney and Jones (2010). In order to obtain the maximum LIG warmth, we perform and analyse transient model scenarios. For the proxy data by CAPE-Last Interglacial Project Members (2006) that represent summer temperatures, changes in the GIS are of minor importance for SSTs.
Throughout the LIG, winter in the northern high latitudes is characterized by high temporal variability, while summer TS indicates a clear cooling trend. By considering transient simulations with different boundary conditions (i.e. GIS elevation, albedo, insolation, GHG concentrations) we offer a spectrum of potential temperatures at each given time throughout the LIG, between 130 and $115 \mathrm{kyr} \mathrm{BP}$. We reduce the mismatch between model and data by additionally considering uncertainties in absolute dating of the proxy reconstructions, and uncertainties in the timing of maximum LIG warmth (calculated in our study as the simulated maximum LIG warmth between 130 and $120 \mathrm{kyr}$ BP at each given location). The missing exact time constraint in CAPE-Last Interglacial Project Members (2006) and Turney and Jones (2010) therefore provides an additional uncertainty and complicates direct model-data comparisons. Future studies that provide a mechanistic multi-proxy interpretation and a better representation of the climate feedbacks are needed in order to reduce the model-data mismatch. Our sensitivity simulations represent a starting point for future studies on transient integrations of the LIG climate that also include transient changes in GIS elevation and extent, as well as for the comparison of such results to high-quality proxy data. More sensitivity studies on the effects of a reduced GIS on global climate are required in order to understand the response of different models to such changes, as the ability of the models to properly simulate future states of the GIS is critical.

\section{The Supplement related to this article is available online at doi:10.5194/cp-12-1313-2016-supplement.}

Acknowledgements. This study was funded by the Deutsche Forschungsgemeinschaft (DFG) under grant agreement no. LO 895/8-1 through the priority programme INTERDYNAMIK (SPP 1266) and is part of the project "Evaluation of Eemian and Holocene Climate Variability: Synthesis of marine archives with climate modelling". We are very grateful to an anonymous referee and Emilie Capron for the in-depth and helpful comments. We thank Valerie Masson-Delmotte for kindly editing our manuscript. We acknowledge Ingo Sasgen for helpful discussions on the manuscript. Furthermore, we thank the many contributors for making the temperature proxy data available. We thank Dan Lunt for providing the formatted proxy-based data set of Turney and Jones (2010) and Emilie Capron for providing their temperature data set.

Edited by: V. Masson-Delmotte

\section{References}

Alley, R. B., Andrews, J. T., Brigham-Grette, J., Clarke, G. K. C., Cuffey, K. M., Fitzpatrick, J. J., Funder, S., Marshall, S. J., 
Miller, G. H., Mitrovica, J. X., Muhs, D. R., Otto-Bliesner, B. L., Polyak, L., and White, J. W. C.: History of the Greenland Ice Sheet: paleoclimatic insights, Quaternary Sci. Rev., 29, 17281756, doi:16/S0277-3791(99)00062-1, 2010.

Bakker, P. and Renssen, H.: Last interglacial model-data mismatch of thermal maximum temperatures partially explained, Clim. Past, 10, 1633-1644, doi:10.5194/cp-10-1633-2014, 2014.

Bakker, P., Van Meerbeeck, C. J., and Renssen, H.: Sensitivity of the North Atlantic climate to Greenland Ice Sheet melting during the Last Interglacial, Clim. Past, 8, 995-1009, doi:10.5194/cp-8995-2012, 2012.

Bakker, P., Stone, E. J., Charbit, S., Gröger, M., Krebs-Kanzow, U., Ritz, S. P., Varma, V., Khon, V., Lunt, D. J., Mikolajewicz, U., Prange, M., Renssen, H., Schneider, B., and Schulz, M.: Last interglacial temperature evolution - a model inter-comparison, Clim. Past, 9, 605-619, doi:10.5194/cp-9-605-2013, 2013.

Bakker, P., Masson-Delmotte, V., Martrat, B., Charbit, S., Renssen, H., Gröger, M., Krebs-Kanzow, U., Lohman, G., Lunt, D. J., Pfeiffer, M., Phipps, S. J., Prange, M., Ritz, S. P., Schulz, M., Stenni, B., Stone, E. J., and Varma, V.: Temperature trends during the Present and Last Interglacial periods - a multimodel-data comparison, Quaternary Sci. Rev., 99, 224-243, doi:10.1016/j.quascirev.2014.06.031, 2014.

Barbi, D., Lohmann, G., Grosfeld, K., and Thoma, M.: Ice sheet dynamics within an earth system model: downscaling, coupling and first results, Geosci. Model Dev., 7, 2003-2013, doi:10.5194/gmd-7-2003-2014, 2014.

Bauch, H. A. and Erlenkeuser, H.: Interpreting glacial-interglacial changes in ice volume and climate from subarctic deep water foraminiferal $\delta^{18} \mathrm{O}$, in: Earth's Climate and Orbital Eccentricity: The Marine Isotope Stage 11 Question, edited by: Droxler, A. W., Poore, R. Z., and Burckle, L. H., American Geophysical Union Monograph Series, Washington DC, 87-102, doi:10.1029/137GM07, 2003.

Berger, A. and Loutre, M. F.: Insolation values for the climate of the last 10 million years, Quaternary Sci. Rev., 10, 297-317, doi:10.1016/0277-3791(91)90033-Q, 1991.

Berger, A. L.: Long-term variations of daily insolation and Quaternary climatic changes, J. Atmos. Sci., 35, 2362-2367, 1978.

Braconnot, P., Otto-Bliesner, B., Harrison, S., Joussaume, S., Peterchmitt, J.-Y., Abe-Ouchi, A., Crucifix, M., Driesschaert, E., Fichefet, Th., Hewitt, C. D., Kageyama, M., Kitoh, A., Loutre, M.-F., Marti, O., Merkel, U., Ramstein, G., Valdes, P., Weber, L., Yu, Y., and Zhao, Y.: Results of PMIP2 coupled simulations of the Mid-Holocene and Last Glacial Maximum - Part 2: feedbacks with emphasis on the location of the ITCZ and mid- and high latitudes heat budget, Clim. Past, 3, 279-296, doi:10.5194/cp-3-279-2007, 2007.

Braconnot, P., Harrison, S., Kageyama, M., Bartlein, P., MassonDelmotte, V., Abe-Ouchi, A., Otto-Bliesner, B., and Zhao, Y.: Evaluation of climate models using palaeoclimatic data, Nature Climate Change, 2, 417-424, doi:10.1038/nclimate1456, 2012.

Brewer, S., Guiot, J., and Torre, F.: Mid-Holocene climate change in Europe: a data-model comparison, Clim. Past, 3, 499-512, doi:10.5194/cp-3-499-2007, 2007.

Brovkin, V., Raddatz, T., Reick, C. H., Claussen, M., and Gayler, V.: Global biogeophysical interactions between forest and climate, Geophys. Res. Lett., 36, L07405, doi:10.1029/2009GL037543, 2009.
CAPE-Last Interglacial Project Members: Last Interglacial Arctic warmth confirms polar amplification of climate change, Quaternary Sci. Rev., 25, 1383-1400, doi:10.1016/j.quascirev.2006.01.033, 2006.

Capron, E., Govin, A., Stone, E. J., Masson-Delmotte, V., Mulitza, S., Otto-Bliesner, B. L., Rasmussen, T. L., Sime, L. C., Waelbroeck, C., and Wolff, E. W.: Temporal and spatial structure of multi-millennial temperature changes at high latitudes during the Last Interglacial, Quaternary Sci. Rev., 103, 116-133, doi:10.1016/j.quascirev.2014.08.018, 2014.

Carlson, A. E., Stoner, J. S., Donnelly, J. P., and Hillaire-Marcel, C.: Response of the southern Greenland Ice Sheet during the last two deglaciations, Geology, 36, 359-362, doi:10.1130/G24519A.1, 2008.

Chiu, T.-C., Fairbanks, R. G., Cao, L., and Mortlock, R. A.: Analysis of the atmospheric ${ }^{14} \mathrm{C}$ record spanning the past 50,000 years derived from high-precision ${ }^{230} \mathrm{Th} /{ }^{234} \mathrm{U} /{ }^{238} \mathrm{U}$ and ${ }^{231} \mathrm{~Pa} /{ }^{235} \mathrm{U}$ and ${ }^{14} \mathrm{C}$ dates on fossil corals, Quaternary Sci. Rev., 26, 18-36, doi:10.1016/j.quascirev.2006.06.015, 2007.

Church, J. A., Clark, P. U., Cazenave, A., Gregory, J. M., Jevrejeva, S., Levermann, A., Merrifield, M. A., Milne, G. A., Nerem, R. S., Nunn, P. D., Payne, A. J., Pfeffer, W. T., Stammer, D., and Unnikrishnan, A. S.: Sea level change, in: Climate Change 2013: The Physical Science Basis, Contribution of Working Group I to the Fifth Assessment Report of the Intergovernmental Panel on Climate Change, edited by: Stocker, T. F., Qin, D., Plattner, G.K., Tignor, M., Allen, S. K., Boschung, J., Nauels, A., Xia, Y., Bex, V., and Midgley, P. M., Cambridge University Press, Cambridge, UK and New York, USA, 1137-1216, 2013.

CLIMAP Project Members: The Last Interglacial ocean, Quaternary Res., 21, 123-224, 1984.

Collins, M., Knutti, R., Arblaster, J., Dufresne, J.-L., Fichefet, T., Friedlingstein, P., Gao, X., Gurowki, W. J., Johns, T., Krinner, G., Shongwe, M., Tebaldi, C., Weaver, A. J., and Wehner, M. Long-term climate change: projections, commitments and irreversibility, in: Climate Change 2013: The Physical Science Basis, Contribution of Working Group I to the Fifth Assessment Report of the Intergovernmental Panel on Climate Change, edited by: Stocker, T. F., Qin, D., Plattner, G.-K., Tignor, M., Allen, S. K., Boschung, J., Nauels, A., Xia, Y., Bex, V., and Midgley, P. M., Cambridge University Press, Cambridge, UK and New York, USA, 1029-1136, 2013.

Colville, E. J., Carlson, A. E., Beard, B. L., Hatfield, R. G., Stoner, J. S., Reyes, A. V., and Ullman, D. J.: Sr-Nd-Pb isotope evidence for ice-sheet presence on southern Greenland during the last interglacial, Science, 333, 620-623, doi:10.1126/science.1204673, 2011.

Crowley, T. J. and Kim, K.-Y.: Milankovitch forcing of the Last Interglacial sea level, Science, 265, 1566-1568, 1994.

Cuffey, K. M. and Marshall, S. J.: Substantial contribution to sealevel rise during the last interglacial from the Greenland ice sheet, Nature, 404, 591-594, doi:10.1038/35007053, 2000.

Dima, M. and Lohmann, G.: Evidence for Two Distinct Modes of Large-Scale Ocean Circulation Changes over the Last Century, J. Climate, 23, 5-16, doi:10.1175/2009JCLI2867.1, 2010.

Dowsett, H. J., Foley, K. M., Stoll, D. K., Chandler, M. A., Sohl, L. E., Bentsen, M., Otto-Bliesner, B. L., Bragg, F. J., Chan, W.-L., Contoux, C., Dolan, A. M., Haywood, A. M., Jonas, J. A., Jost, A., Kamae, Y., Lohmann, G., Lunt, D. J., Nisancioglu, K. H., 
Abe-Ouchi, A., Ramstein, G., Riesselman, C. R., Robinson, M. M., Rosenbloom, N. A., Salzmann, U., Stepanek, C., Strother, S. L., Ueda, H., Yan, Q., and Zhang, Z.: Sea surface temperature of the mid-Piacenzian ocean: a data-model comparison, Scientific Reports, 3, 2013, doi:10.1038/srep02013, 2013.

Drysdale, R. N., Hellstrom, J. C., Zanchetta, G., Fallick, A. E., Sánchez-Goñi, M. F., Couchoud, I., McDonald, J., Maas, R., Lohmann, G., and Isola, I.: Evidence for obliquity forcing of glacial Termination II, Science, 325, 1527-1531, doi:10.1126/science.1170371, 2009.

Dutton, A. and Lambeck, K.: Ice volume and sea level during the last interglacial, Science, 337, 216-219, doi:10.1126/science.1205749, 2012.

Dutton, A., Carlson, A., Milne, G., Long, A. J., Clark, P. U., DeConto, R., Horton, B. P., Rahmstorf, S., and Raymo, M. E.: Sealevel rise due to polar ice-sheet mass loss during past warm periods, Science, 349, 6244, doi:10.1126/science.aaa4019, 2015.

Eugster, W., Rouse, W., Pielke Sr., R. A., McFadden, J. P., Baldocchi, D., Kittel, D., Chapin III, T. G. F., Liston, F. S., Vidale, G. E., Vaganov, P. L., and Chambers, E. S.: Land-atmosphere energy exchange in Arctic tundra and boreal forest: available data and feedbacks to climate, Glob. Change Biol., 6, 84-115, doi:10.1046/j.1365-2486.2000.06015.x, 2000.

Fairbanks, R. G., Mortlock, R. A., Chiu, T.-C., Cao, L., Kaplan, A., Guilderson, T. P., Fairbanks, T. W., Bloom, A. L., Grootes, P. M., and Nadeau, M.-J.: Radiocarbon calibration curve spanning 0 to 50,000 years BP based on paired ${ }^{230} \mathrm{Th} /{ }^{234} \mathrm{U} /{ }^{238} \mathrm{U}$ and ${ }^{14} \mathrm{C}$ dates on pristine corals, Quaternary Sci. Rev., 24, 1781-1796, doi:10.1016/j.quascirev.2005.04.007, 2005.

Felis, T., Lohmann, G., Kuhnert, H., Lorenz, S. J., Scholz, D., Pätzold, J., Al Rousan, S. A., and Al-Moghrabi, S. M.: Increased seasonality in Middle East temperatures during the last interglacial period, Nature, 429, 164-168, doi:10.1038/nature02546, 2004.

Felis, T., Giry, C., Scholz, D., Lohmann, G., Pfeiffer, M., Pätzold, J., Kölling, M., and Scheffers, S. R.: Tropical Atlantic temperature seasonality at the end of the last interglacial, Nature Communications, 6, 6159, doi:10.1038/ncomms7159, 2015.

Fitzjarrald, D. R. and Moore, K. E.: Turbulent transport over tundra, J. Geophys. Res.-Atmos., 97, 16717-16729, doi:10.1029/91JD01030, 1992.

Flato, G., Marotzke, J., Abiodun, B., Braconnot, P., Chou, S. C., Collins, W., Cox, P., Driouech, F., Emori, S., Eyring, V., Forest, C., Gleckler, P., Guilyardi, E., Jakob, C., Kattsov, V., Reason, C., and Rummukainen, M.: Evaluation of climate models, in: Climate Change 2013: The Physical Science Basis, Contribution of Working Group I to the Fifth Assessment Report of the Intergovernmental Panel on Climate Change, edited by: Stocker, T. F., Qin, D., Plattner, G.-K., Tignor, M., Allen, S. K., Boschung, J., Nauels, A., Xia, Y., Bex, V., and Midgley, P. M., Cambridge University Press, Cambridge, UK and New York, USA, 741-866, 2013.

Fowler, C. M. R.: The Solid Earth: an introduction to global geophysics, Cambridge University Press, Cambridge, UK, doi:10.1017/CBO9780511819643, 2004.

Gauss, C. F. and Stewart, G. W.: Theory of the Combination of Observations Least Subject to Error: Part One, Part Two, Supplement, vol. 11, Classics in Applied Math- ematics, Society for Industrial and Applied Mathematics, doi:10.1137/1.9781611971248, 1995.

Gierz, P., Lohmann, G., and Wei, W.: Response of Atlantic Overturning to Future Warming in a coupled AtmosphereOcean-Ice Sheet Model, Geophys. Res. Lett., 42, 6811-6818, doi:10.1002/2015GL065276, 2015.

Gong, X., Knorr, G., Lohmann, G., and Zhang, X.: Dependence of abrupt Atlantic meridional ocean circulation changes on climate background states, Geophys. Res. Lett., 40, 3698-3704, doi:10.1002/grl.50701, 2013.

Gong, X., Zhang, X., Lohmann, G., Wei, W., Zhang, X., and Pfeiffer, M.: Higher Laurentide and Greenland ice sheets strengthen the North Atlantic ocean circulation, Clim. Dynam., 45, 139150, doi:10.1007/s00382-015-2502-8, 2015.

Govin, A., Braconnot, P., Capron, E., Cortijo, E., Duplessy, J.-C., Jansen, E., Labeyrie, L., Landais, A., Marti, O., Michel, E., Mosquet, E., Risebrobakken, B., Swingedouw, D., and Waelbroeck, C.: Persistent influence of ice sheet melting on high northern latitude climate during the early Last Interglacial, Clim. Past, 8, 483-507, doi:10.5194/cp-8-483-2012, 2012.

Govin, A., Capron, E., Tzedakis, P. C., Verheyden, S., Ghaleb, B., Hillaire-Marcel, C., St-Onge, G., Stoner, J. S., Bassinot, F., Bazin, L., Blunier, T., Combourieu Nebout, N., El Quahabi, A., Genty, D., Gersonde, R., Jiminez-Amat, P., Landais, A., Martrat, B., Masson-Delmotte, V., Parrenin, F., Seidenkrantz, M. S., Veres, D., Waelbroeck, C., and Zahn, R.: Sequence of events from the onset to the demise of the Last Interglacial: evaluating strengths and limitations of chronologies used in climatic archives, Quaternary Sci. Rev., 129, 1-36, doi:10.1016/j.quascirev.2015.09.018, 2015.

Harrison, S. P., Kutzbach, J. E., Prentice, C. E., Behling, P. J., and Sykes, M. T.: The response of Northern Hemisphere extratropical climate and vegetation to orbitally induced changes in insolation during the last interglaciation, Quaternary Res., 43, 174184, doi:10.1006/qres.1995.1018, 1995.

Herold, M. and Lohmann, G.: Eemian tropical and subtropical African moisture transport: an isotope modelling study, Clim. Dynam., 33, 1075-1088, doi:10.1007/s00382-008-0515-2, 2009.

Hibler, W.: Dynamic thermodynamic sea ice model, J. Phys. Oceanogr., 9, 815-846, 1979.

Jansen, E., Overpeck, J., Briffa, K. R., Duplessy, J.-C., Joos, F., Masson-Delmotte, V., Olago, D., Otto-Bliesner, B., Peltier, W. R., Rahmstorf, S., Ramesh, R., Raynaud, D., Rind, D., Solomina, O., Villalba, R., and Zhang, D.: Palaeoclimate, in: Climate Change 2007: The Physical Science Basis, Contribution of Working Group I to the Fourth Assessment Report of the Intergovernmental Panel on Climate Change, edited by: Solomon, S., Qin, D., Manning, M., Chen, Z., Marquis, M., Averyt, K. B., Tignor, M., and Miller, H. L., Cambridge University Press, Cambridge, UK and New York, USA, 433-497, 2007.

Jennings, R., Singarayer, J., Stone, E. J., Krebs-Kanzow, U., Khon, V., Nisancioglu, K. H., Pfeiffer, M., Zhang, X., Parker, A. G., Parton, A., Groucutt, H. S., White, T. S., Drake, N. A., and Petraglia, M. D.: The greening of Arabia: multiple opportunities for human occupation of the Arabian Peninsula during the Late Pleistocene inferred from an ensemble of climate model simulations, Quatern. Int., 382, 181-199, doi:10.1016/j.quaint.2015.01.006, 2015. 
Johnsen, S. J. and Vinther, B. M.: Greenland stable isotopes, in: Encyclopedia of Quaternary Science, Elsevier, 1250-1258, doi:10.1016/B0-444-52747-8/00345-8, 2007.

Joussaume, S. and Braconnot, P.: Sensitivity of paleoclimate simulation results to season definitions, J. Geophys. Res., 102, 19431956, doi:10.1029/96JD01989, 1997.

Jungclaus, J. H., Keenlyside, N., Botzet, M., Haak, H., Luo, J. J., Latif, M., Marotzke, J., Mikolajewicz, U., and Roeckner, E.: Ocean circulation and tropical variability in the coupled model ECHAM5/MPI-OM, J. Climate, 19, 3952-3972, doi:10.1175/JCLI3827.1, 2006.

Kaspar, F. and Cubasch, U.: Simulations of the Eemian interglacial and the subsequent glacial inception with a coupled ocean atmosphere general circulation model, in: The Climate of Past Interglacials, edited by: Sirocko, F., Litt, T., Claussen, M., and Sánchez-Goñi, M. F., Elsevier, Developments in Quaternary Sciences, 7, Chap. 33, 499-515, doi:10.1016/S15710866(07)80058-3, 2007.

Kaspar, F., Kühl, N., Cubasch, U., and Litt, T.: A model-data comparison of European temperatures in the Eemian interglacial, Geophys. Res. Lett., 32, L11703, doi:10.1029/2005GL022456, 2005.

Kirtman, B., Power, S. B., Adedoyin, J. A., Boer, G. J., Bojariu, R., Camilloni, I., Doblas-Reyes, F. J., Fiore, A. M., Kimoto, M., Meehl, G. A., Prather, M., Sarr, A., Schär, C., Sutton, R., van Oldenborgh, G. J., Vecchi, G., and Wang, H. J.: Near-term climate change: projections and predictability, in: Climate Change 2013: The Physical Science Basis. Contribution of Working Group I to the Fifth Assessment Report of the Intergovernmental Panel on Climate Change, edited by: Stocker, T. F., Qin, D., Plattner, G.-K., Tignor, M., Allen, S. K., Boschung, J., Nauels, A., Xia, Y., Bex, V., and Midgley, P. M., Cambridge University Press, Cambridge, UK and New York, USA, 953-1028, 2013.

Knight, R. A., Allan, R. J., Folland, C. K., Vellinga, M., and Mann, M. E. A.: A signature of persistent natural thermohaline circulation cycles in observed climate, Geophys. Res. Lett., 32, L20708, doi:10.1029/2005GL024233, 2005.

Knorr, G. and Lohmann, G.: A warming climate during the Antarctic ice sheet growth at the Middle Miocene transition, Nat. Geosci., 7, 376-381, doi:10.1038/NGEO2119, 2014.

Knorr, G., Butzin, M., Micheels, A., and Lohmann, G.: A warm Miocene climate at low atmospheric $\mathrm{CO}_{2}$ levels, Geophys. Res. Lett., 38, L20701, doi:10.1029/2011GL048873, 2011.

Koerner, R. M.: Ice-core evidence for extensive melting of the Greenland Ice Sheet in the last interglacial, Science, 244, 964968, 1989

Koerner, R. M. and Fisher, D. A.: Ice-core evidence for widespread Arctic glacier retreat in the last interglacial and the early Holocene, Ann. Glaciol., 35, 19-24, doi:10.3189/172756402781817338, 2002.

Kopp, R. E., Simons, F. J., Mitrovica, J. X., Maloof, A., and Oppenheimer, M.: Probabilistic assessment of sea level during the last interglacial stage, Nature, 462, 863-867, doi:10.1038/nature08686, 2009.

Kopp, R. E., Simons, F. J., Mitrovica, J. X., Maloof, A., and Oppenheimer, M.: Probabilistic assessment of sea level variations within the last interglacial stage, Geophys. J. Int., 193, 711-716, doi:10.1093/gji/ggt029, 2013.
Kukla, G. J., Bender, M. L., de Beaulieu, J. L., Bond, G., Broecker, W. S., Cleveringa, P., Gavin, J. E., Herbert, T. D., Imbrie, J., Jouzel, J., Keigwin, L. D., Knudsen, K.-L., McManus, J. F., Merkt, J., Muhs, D. R., Müller, H., Poore, R. Z., Porter, S. C., Seret, G., Shackleton, N. J., Turner, C., Tzedakis, P. C., and Winograd, I. J.: Last interglacial climates, Quaternary Res., 58, 2-13, doi:10.1006/qres.2001.2316, 2002.

Kutzbach, J. E., Gallimore, R. G., and Guetter, P. J.: Sensitivity experiments on the effect o orbitally-caused insolation changes on the interglacial climate of high northern latitudes, Quatern. Int., 10-12, 223-229, doi:10.1016/1040-6182(91)90054-R, 1991.

Landais, A., Masson-Delmotte, V., Capron, E., Langebroek, P. M., Bakker, P., Stone, E. J., Merz, N., Raible, C. C., Fischer, H., Orsi, A., Prié, F., Vinther, B., and Dahl-Jensen, D.: How warm was Greenland during the last interglacial period?, Clim. Past Discuss., doi:10.5194/cp-2016-28, in review, 2016.

Langebroek, P. M. and Nisancioglu, K. H.: Simulating last interglacial climate with NorESM: role of insolation and greenhouse gases in the timing of peak warmth, Clim. Past, 10, 1305-1318, doi:10.5194/cp-10-1305-2014, 2014.

Laskar, J., Robutel, P., Joutel, F., Gastineau, M., Correia, A. C. M., and Levrard, B.: A long-term numerical solution for the insolation quantities of the Earth, Astron. Astrophys., 428, 261-285, doi:10.1051/0004-6361:20041335, 2004.

Latif, M., Boning, C., Willebrand, J., Biastoch, A., Dengg, J., Keenlyside, N., Schweckendiek, U., and Madec, G.: Is the thermohaline circulation changing?, J. Climate, 19, 4631-4637, doi:10.1175/JCLI3876.1, 2006.

Leduc, G., Schneider, R. R., Kim, J. H., and Lohmann, G.: Holocene and Eemian sea surface temperature trends as revealed by alkenone and $\mathrm{Mg} / \mathrm{Ca}$ paleothermometry, Quaternary Sci. Rev., 29, 989-1004, doi:10.1016/j.quascirev.2010.01.004, 2010.

Lhomme, N., Clarke, G. K. C., and Ritz, C.: Global budget of water isotopes inferred from polar ice sheets, Geophys. Res. Lett., 32, L20502, doi:10.1029/2005GL023774, 2005.

Lisiecki, L. E. and Raymo, M. E.: A Pliocene-Pleistocene stack of 57 globally distributed benthic $\delta^{18} \mathrm{O}$ records, Paleoceanography, 20, PA1003, doi:10.1029/2004PA001071, 2005.

Lohmann, G. and Lorenz, S. J.: Orbital forcing on atmospheric dynamics during the last interglacial and glacial inception, in: The Climate of Past Interglacials, edited by: Sirocko, F., Claussen, M., Sánchez-Goñi, M. F., and Litt, T., Elsevier, Developments in Quaternary Science, 7, 527-546, 2007.

Lohmann, G., Pfeiffer, M., Laepple, T., Leduc, G., and Kim, J.-H.: A model-data comparison of the Holocene global sea surface temperature evolution, Clim. Past, 9, 1807-1839, doi:10.5194/cp-9-1807-2013, 2013.

Lorenz, S. J. and Lohmann, G.: Acceleration technique for Milankovitch type forcing in a coupled atmosphere-ocean circulation model: method and application for the Holocene, Clim. Dynam., 23, 727-743, doi:10.1007/s00382-004-0469-y, 2004.

Loulergue, L., Schilt, A., Spahni, R., Masson-Delmotte, V., Blunier, T., Lemieux, B., Barnola, J.-M., Raynaud, D., Stocker, T. F., and Chappellaz, J.: Orbital and millennial-scale features of atmospheric $\mathrm{CH}_{4}$ over the past 800,000 years, Nature, 453, 383386, doi:10.1038/nature06950, 2008.

Loutre, M. F., Fichefet, T., Goosse, H., Huybrechts, P., Goelzer, H., and Capron, E.: Factors controlling the last interglacial climate 
as simulated by LOVECLIM1.3, Clim. Past, 10, 1541-1565, doi:10.5194/cp-10-1541-2014, 2014.

Lunt, D. J., Abe-Ouchi, A., Bakker, P., Berger, A., Braconnot, P., Charbit, S., Fischer, N., Herold, N., Jungclaus, J. H., Khon, V. C., Krebs-Kanzow, U., Langebroek, P. M., Lohmann, G., Nisancioglu, K. H., Otto-Bliesner, B. L., Park, W., Pfeiffer, M., Phipps, S. J., Prange, M., Rachmayani, R., Renssen, H., Rosenbloom, N., Schneider, B., Stone, E. J., Takahashi, K., Wei, W., Yin, Q., and Zhang, Z. S.: A multi-model assessment of last interglacial temperatures, Clim. Past, 9, 699-717, doi:10.5194/cp-9-699-2013, 2013.

Lüthi, D., Le Floch, M., Bereiter, B., Blunier, T., Barola, J. M., Siegenthaler, U., Raynaud, D., Jouzel, J., Fischer, H., Kawamur, K., and Stocker, T. F.: High-resolution carbon dioxide concentration record 650,00-800,000 years before present, Nature, 453, 379-382, doi:10.1038/nature06949, 2008.

Marsland, S. J., Haak, H., Jungclaus, J. H., Latif, M., and Röske, F.: The Max-Planck-Institute global ocean/sea ice model with orthogonal curvilinear coordinates, Ocean Model., 5, 91-127, doi:10.1016/S1463-5003(02)00015-X, 2003.

Martinson, D. G., Pisias, N. G., Hays, J. D., Imbrie, J. D., Moore, T. C., and Shackleton, N. J.: Age Dating and the orbital theory of the ice ages: development of a high-resolution 0 to 300,000-year chronostratigraphy, Quaternary Res., 27, 1-29, doi:10.1016/0033-5894(87)90046-9, 1987.

Masson-Delmotte, V., Kageyama, M., Braconnot, P., Charbit, S., Krinner, G., Ritz, C., Guilyardi, E., Jouzel, J., Abe-Ouchi, A., Crucifix, M., Gladstone, R. M., Hewitt, C. D., Kitoh, A., LeGrande, A. N., Marti, O., Merkel, U., Motoi, T., Ohgaito, R., Otto-Bliesner, B., Peltier, W. R., Ross, I., Valdes, P. J., Vettoretti, G., Weber, S. L., Wolk, F., and Yu, Y.: Past and future polar amplification of climate change: climate model intercomparisons and ice-core constraints, Clim. Dynam., 26, 513-529, doi:10.1007/s00382-005-0081-9, 2006.

Masson-Delmotte, V., Braconnot, P., Hoffmann, G., Jouzel, J., Kageyama, M., Landais, A., Lejeune, Q., Risi, C., Sime, L., Sjolte, J., Swingedouw, D., and Vinther, B.: Sensitivity of interglacial Greenland temperature and $\delta^{18} \mathrm{O}$ : ice core data, orbital and increased $\mathrm{CO}_{2}$ climate simulations, Clim. Past, 7, 10411059, doi:10.5194/cp-7-1041-2011, 2011.

Masson-Delmotte, V., Schulz, M., Abe-Ouchi, A., Beer, J., Ganopolski, A., González Rouco, J. F., Jansen, E., Lambeck, K., Luterbacher, J., Naish, T., Osborn, T., Otto-Bliesner, B., Quinn, T., Ramesh, R., Rojas, M., Shao, X., and Timmermann, A.: Information from Paleoclimate archives, in: Climate Change 2013: The Physical Science Basis, Contribution of Working Group I to the Fifth Assessment Report of the Intergovernmental Panel on Climate Change, edited by: Stocker, T. F., Qin, D., Plattner, G.K., Tignor, M., Allen, S. K., Boschung, J., Nauels, A., Xia, Y., Bex, V., and Midgley, P. M., Cambridge University Press, Cambridge, UK and New York, USA, 383-464, 2013.

McKay, N. P., Overpeck, J. T., and Otto-Bliesner, B. L.: The role of ocean thermal expansion in Last Interglacial sea level rise, Geophys. Res. Lett., 38, L14605, doi:10.1029/2011GL048280, 2011.

Mearns, L. O., Hulme, M., Carter, T. R., Leemans, R., Lal, M., and Whetton, P.: Climate scenario development, in: Climate Change 2001: The Scientific Basis, Contribution of Working Group I to the Third Assessment Report of the Intergovernmental Panel on
Climate Change, edited by: Houghton, J. T., Ding, Y., Griggs, D. J., Noguer, M., van der Linden, P. J., Dai, X., Maskell, K., and Johnson, C. A., Cambridge University Press, Cambridge, UK and New York, USA, 739-768, 2001.

Merz, N., Born, A., Raible, C. C., Fischer, H., and Stocker, T. F.: Dependence of Eemian Greenland temperature reconstructions on the ice sheet topography, Clim. Past, 10, 1221-1238, doi:10.5194/cp-10-1221-2014, 2014.

Montoya, M., von Storch, H., and Crowley, T. J.: Climate simulation for $125 \mathrm{kyr} \mathrm{BP}$ with a coupled ocean-atmosphere general circulation model, J. Climate, 13, 1057-1071, doi:10.1175/15200442(2000)013<1057:CSFKBW>2.0.CO;2, 2000.

Mudelsee, M.: Climate Time Series Analysis, Classical Statistical and Bootstrap Methods, Atmospheric and Oceanographic Sciences Library, vol. 42, Springer, Dordrecht, 2010.

NEEM community members: Eemian interglacial reconstructed from a Greenland folded ice core, Nature, 493, 498-494, doi:10.1038/nature11789, 2013.

New, M., Hulme, M., and Jones, P.: Representing twentieth-century space-time climate variability, Part I: Development of a 1961-90 mean monthly terrestrial climatology, J. Climate, 12, 829-856, doi:10.1175/1520-0442(1999)012<0829:RTCSTC>2.0.CO;2, 1999.

NGRIP members: High-resolution record of Northern Hemisphere climate extending into the last interglacial period, Nature, 431, 147-151, doi:10.1038/nature02805, 2004.

O'ishi, R. and Abe-Ouchi, A.: Polar amplification in the mid-Holocene derived from dynamical vegetation change with a GCM, Geophys. Res. Lett., 38, L14702, doi:10.1029/2011GL048001, 2011.

Otto-Bliesner, B. L., Marshall, S. J., Overpeck, J. T., Miller, G. H., Hu, A., and CAPE-Last Interglacial Project members: simulating Arctic Climate Warmth and Icefield Retreat in the Last Interglaciation, Science, 311, 1751-1753, doi:10.1126/science.1120808, 2006.

Otto-Bliesner, B. L., Rosenbloom, N., Stone, E. J., McKay, N. P., Lunt, D. J., Brady, E. C., and Overpeck, J. T.: How warm was the last interglacial? New model - data comparisons, Philos. T. R. Soc. A, 371, 1-20, doi:10.1098/rsta.2013.0097, 2013.

Overpeck, J. T., Otto-Bliesner, B. L., Miller, G. H., Muhs, D. R., Alley, R. B., and Kiehl, J. T.: Paleoclimatic evidence for future ice-sheet instability and rapid sea-level rise, Science, 311, 17471750, doi:10.1126/science.1115159, 2006.

Pfeiffer, M. and Lohmann, G.: The Last Interglacial as simulated by an Atmosphere-Ocean General Circulation Model: sensitivity studies on the influence of the Greenland Ice Sheet, in: Earth System Science: bridging the Gaps between Disciplines Perspectives from a Multi-disciplinary Helmholtz Research School, edited by: Lohmann, G., Grosfeld, K., Wolf-Gladrow, D., Unnithan, V., Notholt, J., and Wegner, A., Series: SpringerBriefs in Earth System Sciences, Springer, Heidelberg, 57-64, doi:10.1007/978-3642-32235-8, 2013.

Quiquet, A., Ritz, C., Punge, H. J., and Salas y Mélia, D.: Greenland ice sheet contribution to sea level rise during the last interglacial period: a modelling study driven and constrained by ice core data, Clim. Past, 9, 353-366, doi:10.5194/cp-9-353-2013, 2013.

Raddatz, T. J., Reick, C. H., Knorr, W., Kattge, J., Roeckner, E., Schnur, R., Schnitzler, K. G., Wetzel, P., and Jungclaus, J.: Will 
the tropical land biosphere dominate the climate-carbon cycle feedback during the twenty-first century?, Clim. Dynam., 29, 565-574, doi:10.1007/s00382-007-0247-8, 2007.

Reimer, P. J., Baillie, M. G. L., Bard, E., Bayliss, A., Beck, J. W., Blackwell, P. G., Bronk Ramsey, C., Buck, C. E., Burr, G. S., Edwards, R. L., Friedrich, M., Grootes, P. M., Guilderson, T. P., Hajdas, I., Heaton, T. J., Hogg, A. G., Hughen, K. A., Kaiser, K. F., Kromer, B., McCormac, F. G., Manning, S. W., Reimer, R. W., Richards, D. A., Southon, J. R., Talamo, S., Turney, C. S. M., van der Plicht, J., and Weyhenmeyer, C. E.: IntCal09 and Marine09 radiocarbon age calibration curves, 0-50,000 years cal BP, Radiocarbon, 51, 1111-1150, 2009.

Reimer, P. J., Bard, E., Bayliss, A., Beck, J. W., Blackwell, P. G., Bronk Ramsey, C., Buck, C. E., Cheng, H., Edwards, R. L., Friedrich, M., Grootes, P. M., Guilderson, T. P., Haflidason, H., Hajdas, I., Hatté, C., Heaton, T. J., Hoffmann, D. L., Hogg, A. G., Hughen, K. A., Kaiser, K. F., Kromer, B., Manning, S. W., Niu, M., Reimer, R. W., Richards, D. A., Scott, E. M., Southon, J. R., Staff, R. A., Turney, C. S. M., and van der Plicht, J.: IntCal13 and Marine13 radiocarbon age calibration curves 0-50,000 years cal BP, Radiocarbon, 55, 1869-1887, doi:10.2458/azu_js_rc.55.16947, 2013.

Renssen, H., Goosse, H., Fichefet, T., Masson-Delmotte, V., and Koç, N: The Holocene climate evolution in the high-latitude Southern Hemisphere simulated by a coupled atmospheresea ice-ocean-vegetation model, Holocene, 15, 951-964, doi:10.1191/0959683605hl869ra, 2005.

Robinson, A., Calov, R., and Ganopolski, A.: Greenland ice sheet model parameters constrained using simulations of the Eemian Interglacial, Clim. Past, 7, 381-396, doi:10.5194/cp-7-381-2011, 2011.

Roeckner, E., Bäuml, G., Bonaventura, L., Brokopf, R., Esch, M., Giorgetta, M., Hagemann, S., Kirchner, I., Kornblueh, L., Manzini, E., Rhodin, A., Schlese, U., Schulzweida, U., and Tompkins, A.: The atmospheric general circulation model ECHAM5, Part I: Model description, Tech. Rep. 349, Max Planck Institute for Meteorology, Hamburg, Germany, 2003.

Schneider, B., Leduc, G., and Park, W.: Disentangling seasonal signals in Holocene climate trends by satellitemodel-proxy integration, Paleoceanography, 25, PA4217, doi:10.1029/2009PA001893, 2010.

Semtner, A. J.: A model for the thermodynamic growth of sea ice in numerical investigations of climate, J. Phys. Oceanogr., 6, 379389, 1976

Shanahan, T. M., Beck, J. W., Overpeck, J. T., McKay, N. P., Pigati, J. S., Peck, J. A., Scholz, C. A., Heil Jr., C. W., and King, J.: Late Quaternary sedimentological and climate changes at Lake Bosumtwi Ghana: new constraints from laminae analysis and radiocarbon age modeling, Palaeogeogr. Palaeocl., 361-362, 49-60, doi:10.1016/j.palaeo.2012.08.001, 2012.

Smith, T. M. and Reynolds, R. W.: A high-resolution global sea surface temperature climatology for the 1961-90 base period, J. Climate, 11, 3320-3323, doi:10.1175/15200442(1998)011<3320:AHRGSS>2.0.CO;2, 1998.

Spahni, R., Chappellaz, J., Stocker, T. F., Loulergue, L., Hausammann, G., Kawamura, K., Fluckiger, J., Schwander, J., Raynaud, D., Masson-Delmotte, V., and Jouzel, J.: Atmospheric methane and nitrous oxide of the late Pleistocene from Antarctic ice cores, Science, 310, 1317-1321, doi:10.1126/science.1120132, 2005.
Stärz, M., Lohmann, G., and Knorr, G.: The effect of a dynamic soil scheme on the climate of the mid-Holocene and the Last Glacial Maximum, Clim. Past, 12, 151-170, doi:10.5194/cp-12151-2016, 2016.

Stepanek, C. and Lohmann, G.: Modelling mid-Pliocene climate with COSMOS, Geosci. Model Dev., 5, 1221-1243, doi:10.5194/gmd-5-1221-2012, 2012.

Stirling, C. H., Esat, T. M., Lambeck, K., and McCulloch, M. T.: Timing and duration of the last interglacial: evidence for a restricted interval of widespread coral reef growth, Earth Planet. Sc. Lett., 160, 745-762, doi:10.1016/S0012-821X(98)00125-3, 1998.

Stone, E. J., Lunt, D. J., Annan, J. D., and Hargreaves, J. C.: Quantification of the Greenland ice sheet contribution to Last Interglacial sea level rise, Clim. Past, 9, 621-639, doi:10.5194/cp-9621-2013, 2013.

Stone, E. J., Capron, E., Lunt, D. J., Payne, A. J., Singarayer, J. S., Valdes, P. J., and Wolff, E. W.: Impact of melt water on high latitude early Last Interglacial climate, Clim. Past Discuss., doi:10.5194/cp-2016-11, in review, 2016.

Sundqvist, H. S., Zhang, Q., Moberg, A., Holmgren, K., Körnich, H., Nilsson, J., and Brattström, G.: Climate change between the mid and late Holocene in northern high latitudes - Part 1: Survey of temperature and precipitation proxy data, Clim. Past, 6, 591608, doi:10.5194/cp-6-591-2010, 2010.

Sutter, J., Gierz, P., Grosfeld, K., Thoma, M., and Lohmann, G.: Ocean temperature thresholds for Last Interglacial West Antarctic Ice Sheet collapse, Geophys. Res. Lett., 43, 2675-2682, doi:10.1002/2016GL067818, 2016.

Tarasov, L. and Peltier, W. R.: Greenland glacial history, borehole constraints, and Eemian extent, J. Geophys. Res., 108, 2143, doi:10.1029/2001JB001731, 2003.

Turney, C. S. M. and Jones, R. T.: Does the Agulhas current amplify global temperatures during super-interglacials?, J. Quaternary Sci., 25, 839-843, doi:10.1002/Jqs.1423, 2010.

Valcke, S.: The OASIS3 coupler: a European climate modelling community software, Geosci. Model Dev., 6, 373-388, doi:10.5194/gmd-6-373-2013, 2013.

Valcke, S., Caubel, A., Declat, D., and Terray, L.: OASIS Ocean Atmosphere Sea Ice Soil users guide, Tech. Rep. TR/CMGC/0369, CERFACS, Toulouse, France, 2003.

van de Berg, W. J., van den Broeke, M., Ettema, J., van Meijgaard, E., and Kaspar, F.: Significant contribution of insolation to Eemian melting of the Greenland ice sheet, Nat. Geosci., 4, 679-683, doi:10.1038/ngeo1245, 2011.

Veeh, H. H.: $\mathrm{Th}^{230} / \mathrm{U}^{238}$ and $\mathrm{U}^{234} / \mathrm{U}^{238}$ ages of Pleistocene high sea level stand, J. Geophys. Res., 71, 3379-3386, 1966.

von Storch, H. and Zwiers, F. W.: Statistical Analysis in Climate Research, Cambridge University Press, New York, 1999.

Wei, W. and Lohmann, G.: Simulated Atlantic Multidecadal Oscillation during the Holocene, J. Climate, 25, 6989-7002, doi:10.1175/JCLI-D-11-00667.1, 2012.

Wei, W., Lohmann, G., and Dima, M.: Distinct modes of internal variability in the global meridional overturning circulation associated with the SH westerly winds, J. Phys. Oceanogr., 42, 785801, doi:10.1175/JPO-D-11-038.1, 2012.

Willerslev, E., Cappellini, E., Boomsma, W., Nielsen, R., Hebsgaard, M. B., Brand, T. B., Hofreiter, M., Bunce, M., Poinar, H. N., Dahl-Jensen, D., Johnsen, S., Steffensen, J. P., Ben- 
nike, O., Schwenninger, J.-L., Nathan, R., Armitage, S., de Hoog, C.-J., Alfimov, V., Christl, M., Beer, J., Muscheler, R., Barker, J., Sharp, M., Penkman, K. E. H., Haile, J., Taberlet, P., Gilbert, M. T. P., Casoli, A., Campani, E., and Collins, M. J.: Ancient bio-molecules from deep ice cores reveal a forested southern Greenland, Science, 317, 111-114, doi:10.1126/science.1141758, 2007.

Yin, Q. Z. and Berger, A.: Insolation and $\mathrm{CO}_{2}$ contribution to the interglacial climate before and after the Mid-Brunhes Event, Nat. Geosci., 3, 243-246, doi:10.1038/ngeo771, 2010.
Zhang, Q., Sundqvist, H. S., Moberg, A., Körnich, H., Nilsson, J., and Holmgren, K.: Climate change between the mid and late Holocene in northern high latitudes - Part 2: Model-data comparisons, Clim. Past, 6, 609-626, doi:10.5194/cp-6-609-2010, 2010.

Zhang, X., Lohmann, G., Knorr, G., and Xu, X.: Different ocean states and transient characteristics in Last Glacial Maximum simulations and implications for deglaciation, Clim. Past, 9, 23192333, doi:10.5194/cp-9-2319-2013, 2013.

Zhang, X., Lohmann, G., Knorr, G., and Purcell, C.: Control of rapid glacial climate shifts by variations in intermediate ice-sheet volume, Nature, 512, 290-294, doi:10.1038/nature13592, 2014. 